\title{
Techno-economic prospects of small-scale membrane reactors in a future hydrogen-fuelled transportation sector
}

\author{
M. Sjardin, K.J. Damen*, A.P.C. Faaij \\ Department of Science, Technology and Society, Copernicus Institute for Sustainable Development and Innovation, \\ Utrecht University, Heidelberglaan 2, 3584 CS Utrecht, The Netherlands
}

Received 30 August 2005

\begin{abstract}
The membrane reactor is a novel technology for the production of hydrogen from natural gas. It promises economic small-scale hydrogen production, e.g. at refuelling stations and has the potential of inexpensive $\mathrm{CO}_{2}$ separation. Four configurations of the membrane reactor have been modelled with Aspen ${ }^{\text {plus }}$ to determine its thermodynamic and economic prospects. Overall energy efficiency is $84 \%_{\mathrm{HHV}}$ without $\mathrm{H}_{2}$ compression ( $78 \%$ with compression up to $482 \mathrm{bar}$ ). The modelling results also indicate that by using a sweep gas, the membrane reactor can produce a reformer exit stream consisting mainly of $\mathrm{CO}_{2}$ and $\mathrm{H}_{2} \mathrm{O}(>90 \%$ mol $)$ suited for $\mathrm{CO}_{2}$ sequestration after water removal with an efficiency loss of only $1 \%$ pt. Reforming with a $2 \mathrm{MW}$ membrane reactor (250 unit production volume) costs $14 \$ / \mathrm{GJ}_{\mathrm{H}_{2}}$ including compression, which is more expensive than conventional steam reforming + compression $(12 \$ / G J)$. It does, however, promise a cheap method of $\mathrm{CO}_{2}$ separation, $14 \$ / \mathrm{t} \mathrm{CO}$ captured, due to the high purity of the exit stream. The well-towheel chain of the membrane reactor has been compared to centralised steam reforming to assess the trade-off between production scale and the construction of a hydrogen and a $\mathrm{CO}_{2}$ distribution infrastructure. If the scale of centralised hydrogen production is below $40 \mathrm{MW}$, the trade-off could be favourable for the membrane reactor with small-scale $\mathrm{CO}_{2}$ capture $\left(18 \$ / G J\right.$ including $\mathrm{H}_{2}$ storage, dispensing and $\mathrm{CO}_{2}$ sequestration for $40 \mathrm{MW} \mathrm{SMR}$ versus $19 \$ / \mathrm{GJ}$ for MR). The membrane reactor might become competitive with conventional steam reforming provided that thin membranes can be combined with high stability and a cheap manufacturing method for the membrane tubes. Thin membranes, industrial utility prices and larger production volumes (i.e. technological learning) might reduce the levelised hydrogen cost of the membrane reactor at the refuelling station to less than $14 \$$ GJ including $\mathrm{CO}_{2}$ sequestration cost, below that of large-scale $\mathrm{H}_{2}$ production with $\mathrm{CO}_{2}$ sequestration $(\sim 15 \$ / \mathrm{GJ})$.

(C) 2006 Elsevier Ltd. All rights reserved.
\end{abstract}

Keywords: Hydrogen; Membrane reactor; Natural gas; Transport; $\mathrm{CO}_{2}$ separation

\section{Introduction}

Driven by concerns over greenhouse gas (GHG) emissions, air quality and security of energy supply, hydrogen has become a contender to replace gasoline and diesel as a future transportation fuel. Used in a fuel cell vehicle (FCV), the efficiency might be 2-3 times higher than current internal combustion engine vehicles

*Corresponding author. Fax: + 31302537601 .

E-mail address: k.j.damen@chem.uu.nl (K.J. Damen). 
(ICEV) whilst emitting solely water vapour. Large-scale plants using fossil feedstock are considered the most economic hydrogen production method [1,2], but major barriers are the cost of building a distribution infrastructure and the need for sufficient demand. Distributed production at refuelling stations, using the already present natural gas infrastructure, is therefore viewed as an attractive near to medium-term option. However, producing hydrogen from fossil fuels such as natural gas still causes significant GHG emissions. The capture and subsequent sequestration of carbon dioxide (the most important GHG) would prevent this, but at small scales (e.g. refuelling stations) this is considered too expensive with conventional reformer technologies [3]. A novel reforming technology, the membrane reactor (MR), is currently being developed and promises economic small-scale hydrogen production combined with inexpensive $\mathrm{CO}_{2}$ capture because of the high concentration and pressure of the exiting gas stream [4]. This could avoid a dedicated hydrogen infrastructure, facilitate $\mathrm{CO}_{2}$ capture at small scales and thus possibly contribute to a more rapid cut in GHG emissions. Since it is expected that significant development of a hydrogen transportation infrastructure will not occur within the next decade [5], the time frame of this study is the medium-term future (2015-2025).

Considerable laboratory research is being conducted into this technology (see e.g. [6-9]) and two companies are seeking to commercialise it: Tokyo Gas Company (TGC) [10] and Membrane Reactor Technologies (MRT) [11]. Several experimental and theoretical studies have examined the thermodynamics of the membrane reactor $[6,12-14,15,16]$ and have shown that the MR can reach higher fuel conversions at lower temperatures than conventional technology [17]. Additional advantages are a simple, compact design and simultaneous reaction and separation. These studies however have only been done on an experimental and theoretical level. Little detailed research has been conducted on the economic viability of the MR from a systems perspective, i.e. specifically assessing the impact of simultaneously reforming and purifying in comparison to using membranes only for purification. For example, Criscuoli et al. [18] have analysed the economics for a membrane system, but only for a water-gas-shift reactor. Other studies only considered largescale applications and demonstrated considerable discrepancies ([19-21,18] and see for an extensive overview [22]). Since especially scale may have an important impact on the economics of the MR and as the technology could be an early candidate for distributed hydrogen production this has been analysed in more detail in this article. In addition, the opportunity of possible inexpensive small-scale $\mathrm{CO}_{2}$ separation has been examined. This leads us to the main questions addressed in this article:

- Can the membrane reactor become a competitive alternative to conventional technology to supply $\mathrm{H}_{2}$ to refuelling stations and which developments are necessary to become cost-effective?

- Can the membrane reactor provide an economically viable opportunity for small-scale $\mathrm{CO}_{2}$ capture, suitable for subsequent sequestration?

The applied methodology and structure of the article are as follows:

1. Technology assessment and selection of suitable configurations (Sections 2 and 3).

2. Collecting technical and economic data on all components of the system through literature and by contacting manufacturers (Section 4).

3. Modelling the membrane reactor configurations in Aspen ${ }^{\text {Plus }}$ to select best operating conditions, evaluate performance and assess sensitivity to different parameters (Sections 5 and 5.2).

4. Economic evaluation of the MR based on component cost (Section 5.3).

5. Comparing the fuel supply chain of the MR with conventional technologies regarding costs (Section 6).

6. Overall conclusions (Section 7).

\section{Technology description of a membrane reactor}

\subsection{Principle}

The principle of the MR is based on steam methane reforming (SMR), currently the most important chemical process for the production of hydrogen or synthesis gas (mixture of mainly $\mathrm{H}_{2}$ and $\mathrm{CO}$ ) [23]. SMR 
consists of three reversible reactions: SMR consists of three reversible reactions:

$$
\begin{aligned}
& \mathrm{CH}_{4}+\mathrm{H}_{2} \mathrm{O}=\mathrm{CO}_{2}+3 \mathrm{H}_{2}, \quad \Delta \mathrm{H}_{298}=206 \mathrm{~kJ} / \mathrm{mol}, \\
& \mathrm{CO}+\mathrm{H}_{2} \mathrm{O}=\mathrm{CO}_{2}+\mathrm{H}_{2}, \quad \Delta \mathrm{H}_{298}=-41 \mathrm{~kJ} / \mathrm{mol}, \\
& \mathrm{CH}_{4}+2 \mathrm{H}_{2} \mathrm{O}=\mathrm{CO}+4 \mathrm{H}_{2}, \quad \Delta \mathrm{H}_{298}=165 \mathrm{~kJ} / \mathrm{mol} .
\end{aligned}
$$

(Reaction 3)

The conventional large-scale process is performed in long tubes filled with nickel-based catalyst particles at pressures of $10-41 \mathrm{bar},{ }^{1}$ temperatures around $850{ }^{\circ} \mathrm{C}$ and steam-to-carbon ratios ( $\mathrm{S} / \mathrm{C}$ ratio) of $2-4$ [13,24]. The reaction is endothermic and required heat is supplied by a natural gas (NG) fuelled furnace. The total hydrogen production process consists of three steps: the steam methane reformer (reaction (1)), a water-gas-shift reactor to enhance $\mathrm{CO}$ conversion (reaction (2)) and hydrogen purification. Purification is generally performed with pressure swing absorption (PSA) to produce $99.99+\%$ hydrogen, a purity level required for proton exchange membrane fuel cells. The membrane reactor can combine these three steps in one reactor (see Fig. 1).

In the MR, a membrane is placed inside the reforming tubes. Whilst the steam reforming reaction takes place, hydrogen is continuously withdrawn from the reaction zone (retentate side) through the membrane (see Fig. 2). Since it is an equilibrium reaction, removing one of the products will shift the equilibrium to the righthand side according to Le Chatelier's principle, resulting in an increase in methane conversion $(\mathrm{MC}=$ methane converted/methane input). Simultaneously, very pure hydrogen is collected on the product side (permeate side) by using a membrane infinitely selective to hydrogen, i.e. no gas other than hydrogen permeates through the membrane. The amount of hydrogen removal is measured by the hydrogen recovery (HR), defined as the molar flow of hydrogen permeated through the membrane divided by the total molar flow of hydrogen produced. Since methane conversion is higher than with conventional methods, the reactor can operate at lower temperatures and still obtain similar MC.

\subsection{Membrane performance}

Palladium is the most widely used membrane material for hydrogen permeation as it is infinitely selective to hydrogen and has demonstrated high permeability. It is usually alloyed with a metal to increase permeability and reduce the effect of hydrogen embrittlement [9,25]. Silver is currently the most popular alloy. Palladiumsilver membranes have proven their suitability for hydrogen permeation in numerous experimental studies (see e.g. [26]) and the fabrication technology is well established. By supporting the metal membrane with porous ceramic substrates $\left(\mathrm{Al}_{2} \mathrm{O}_{3}\right)$, the thickness can be reduced to only several micrometers without compromising stability. Membranes of about $20-50 \mu \mathrm{m}$ thick are commercially available [19]. Thinner membranes $(2-5 \mu \mathrm{m})$ are being produced, but this is as yet only in laboratory settings [27-29]. The main challenge remains producing these membranes without any defects [4]. In this study we assume a $20 \mu \mathrm{m} \mathrm{Pd}_{23} \mathrm{Ag}$ membrane ( $23 \mathrm{vol} \%$ silver) supported by a ceramic substrate and infinitely selective to hydrogen.

Hydrogen atoms permeate through a metal membrane by a solution-diffusion mechanism, following Sievert's law (see Fig. 3) [30]. Under normal conditions, the rate determining step is the diffusion through the membrane as governed by

$$
Q_{\mathrm{H}_{2}}=\frac{K_{0} A}{l}\left[\left(p_{r}\right)^{0.5}-\left(p_{p}\right)^{0.5}\right],
$$

where $Q_{\mathrm{H}_{2}}$ is the $=$ hydrogen permeation rate $(\mathrm{mol} / \mathrm{h}), K_{0}$ the membrane permeability $\left(\mathrm{mol} \mathrm{m} / \mathrm{m}^{2} \mathrm{~h} \mathrm{~Pa}^{0.5}\right), A$ the membrane area $\left(\mathrm{m}^{2}\right), l$ the membrane thickness $(\mathrm{m})$ and $\delta$ the driving force $\left(=p_{r}^{0.5}-p_{p}^{0.5}\right.$ in $\left.\mathrm{Pa}^{0.5}\right)$.

It is important to note that the hydrogen flux is inversely proportional to the membrane thickness. According to a review by Dittmeyer et al. [8], membrane permeability for palladium-based membranes of $1.6 \mathrm{e}^{-8}-2.25 \mathrm{e}^{-5} \mathrm{~mol} \mathrm{~m} / \mathrm{m}^{2} \mathrm{~h} \mathrm{~Pa}{ }^{0.5}$ have been attained in laboratories. We assume a state-of-the-art membrane with a permeability of $2.25 \mathrm{e}^{-5} \mathrm{molm} / \mathrm{m}^{2} \mathrm{hPa}^{0.5}$. The driving force is provided by the partial pressure difference of hydrogen between the two sides. To obtain an adequate partial pressure difference, either a high

\footnotetext{
${ }^{1}$ All pressures are given in bar absolute.
} 


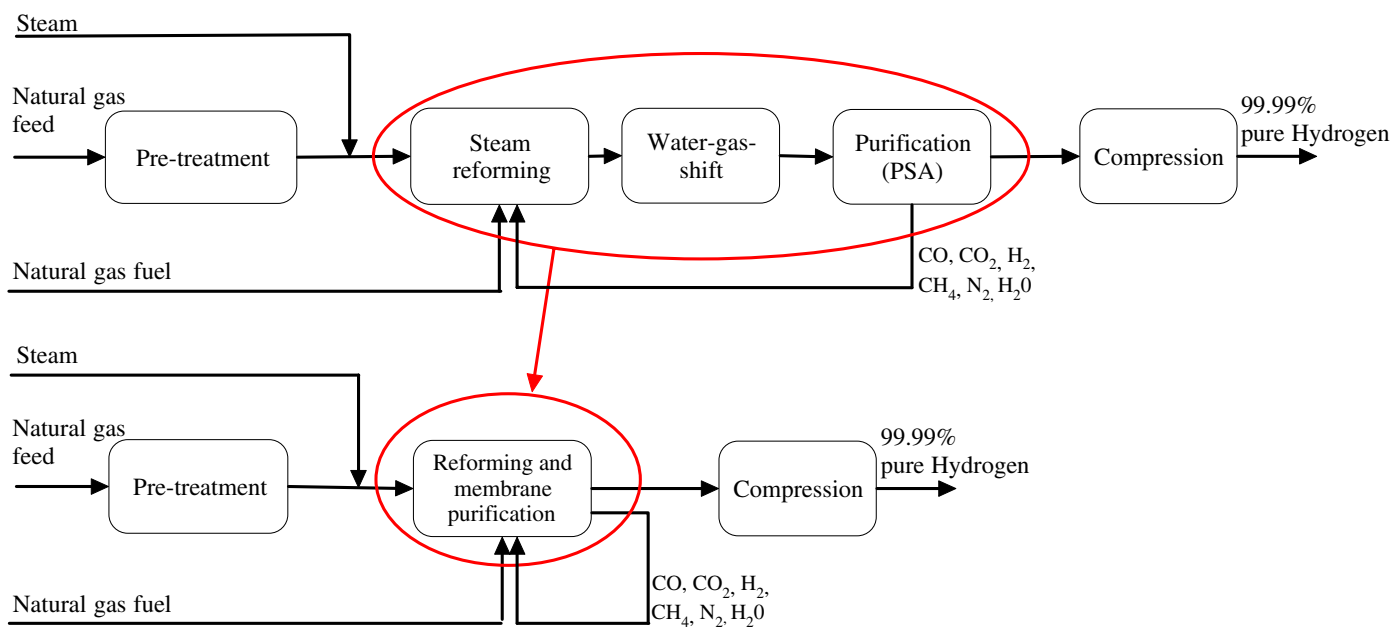

Fig. 1. Process scheme for the SMR and MR.

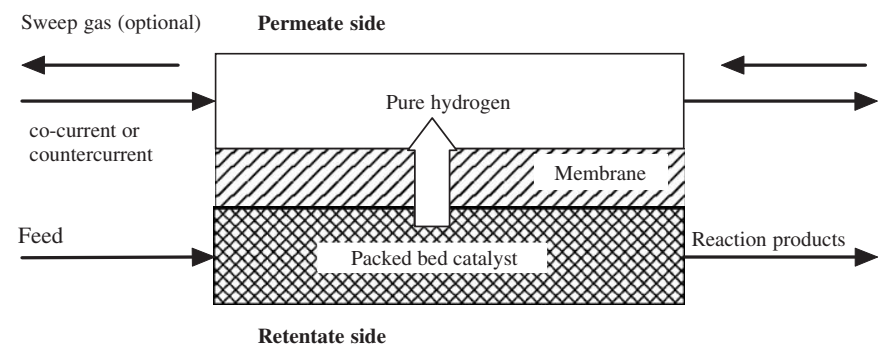

Fig. 2. Principle of the membrane reactor [8].

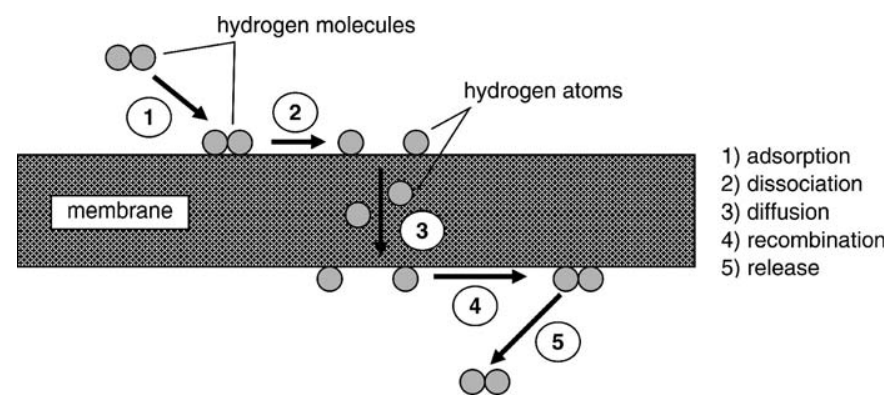

Fig. 3. Hydrogen permeation for a metallic membrane [9].

pressure on the retentate side or a low partial hydrogen pressure on the permeate side is required. The latter can be attained by creating a vacuum on the permeate side or by using a sweep gas to lower the hydrogen concentration. Possible inert sweep gases are steam and nitrogen of which steam is most favoured due to its availability and easy separability from hydrogen (assumed in this study). The sweep gas can either flow cocurrent or counter-current, i.e. flowing in the same direction as the feed flow or in the reverse direction. Previous studies have shown that a counter-current sweep gas is more economic [4,31].

Membrane performance is negatively affected by the presence of other gases and thermal cycling (repeated cycles of cooling and heating the reformer). The presence of sulphur and gases such as nitrogen, steam, CO 
and $\mathrm{CO}_{2}$ can decrease the permeability of the membrane significantly. The negative effect on the permeation rate is caused by the competitive adsorption of these compounds on the hydrogen adsorption sites on the membrane [32]. By increasing the temperature to more than $500{ }^{\circ} \mathrm{C}$, this effect can be greatly reduced [33]. Hence, for temperatures at which the membrane reactor normally operates $\left(500-600{ }^{\circ} \mathrm{C}\right)$, these inhibition effects will not have a serious influence and no negative implications are assumed in our further analysis.

At temperatures around $300^{\circ} \mathrm{C}$ and in the presence of hydrogen, palladium has a transition between two different lattice phases. By continuous heating and cooling, this transition causes membrane stress resulting in microcracks and embrittlement of the membrane [24]. The lifetime of the membrane is therefore strongly dependent on the amount of thermal cycling that it experiences. The negative effect can be partly countered by heating and cooling in the presence of an inert gas such as nitrogen and is hence essential if many start-ups and shut-downs are expected. This adds cost and complexity to the system and may not be sufficient to fully prevent hydrogen embrittlement [34]. Although optimisation of these issues is not investigated here, we assume the amount of thermal cycling should be minimised to ensure a long membrane lifetime (no inert gas is used). Considering the application in the transportation sector, this implies that demand-following operation is not preferred and the focus should be on providing sufficient storage capacity to enable constant operation.

\subsection{Key reactor operating parameters}

Several operating issues have a significant influence on the thermodynamic and economic performance of the MR and make optimisation of the MR a complex problem. The most important process parameters determining its performance (and costs) are temperature, pressure, steam-to-carbon ratio, load-to-surface ratio $(\mathrm{L} / \mathrm{S} \text { ratio })^{2}$ and, when a sweep is used, the sweep ratio. ${ }^{3}$

In a conventional SMR, full methane conversion is reached at about $900{ }^{\circ} \mathrm{C}$ [21]. Hence, at these temperatures no improvement is made with a membrane reactor. The biggest thermodynamic and economic advantages are gained from low-temperature operation, $500-600{ }^{\circ} \mathrm{C}$. A minimum of $500{ }^{\circ} \mathrm{C}$ is required to ensure sufficient methane conversion [13,35]. By reducing the temperature, efficiency can be improved and fuel consumption lowered as less heat is required for the reaction.

In a conventional SMR, the thermodynamic equilibrium shifts to the feed side when reaction pressure is increased, lowering methane conversion. Experimental and modelling results indicate that this effect could be the opposite for the MR, given that the permeation capacity of the membrane is sufficient and enough hydrogen is removed from the reaction site [12,21,36]. An increased reaction pressure causes a higher hydrogen flux through the membrane, more than offsetting the negative thermodynamic effect of pressure on the steam reforming reaction. Thus, higher methane conversion could be attained with higher pressures. High permeation rates reduce membrane area, but also imply increased cost for compressors, pumps and electricity. The optimal value is probably between 10 and 30 bar [14].

An excess of steam is added to the reaction to improve conversion and prevent coke formation. Coke formation is a pervasive problem in steam reforming. The solid reaction product can deactivate the catalyst by depositing on active sites, blocking catalyst pores or causing the metal to separate from the support. It can also block the space, leading to increased bed pressure and eventually obstructing the total flow [37]. Allowing the reaction to proceed to equilibrium at relatively low temperatures and with enough steam, coke formation can be suppressed. The $\mathrm{S} / \mathrm{C}$ ratio for conventional steam reformers is 2.7-3.2 and is sufficient to prevent this [23]. For the MR, the optimal $\mathrm{S} / \mathrm{C}$ ratio is in the same range. Although higher $\mathrm{S} / \mathrm{C}$ ratios increase conversion, the presence of additional steam implies lower hydrogen partial pressure and thus increases membrane surface requirement. In addition, more steam production is needed.

The nominal $\mathrm{L} / \mathrm{S}$ ratio needs to be designed such that at normal operating conditions costs are as low as possible. Obviously, this depends on several parameters. The higher the $\mathrm{L} / \mathrm{S}$ ratio, the less membrane surface is required and thus both capital and operational cost are reduced. On the other hand, a lower $\mathrm{L} / \mathrm{S}$ ratio ensures higher hydrogen recovery and higher methane conversion.

\footnotetext{
${ }^{2} \mathrm{The} \mathrm{L} / \mathrm{S}$ ratio is the molar flow of natural gas feed relative to the membrane surface area.

${ }^{3}$ The sweep ratio is the molar flow of sweep divided by that of the natural gas feed.
} 
Whether a sweep should be used is determined by another trade-off. By using a sweep gas the reactor can operate at lower pressures and still obtain a good driving force [12,38]. Disadvantages are that the sweep needs to be produced, elevated to the reaction temperature and afterwards separated from the hydrogen. The sweep ratio is an important parameter: a higher sweep ratio decreases hydrogen partial pressure on the permeate side, resulting in higher hydrogen recovery due to the increased partial pressure difference. Yet, using more sweep gas requires more heat for steam generation and increases capital cost as additional equipment is required.

\section{4. $\mathrm{CO}_{2}$ separation}

In a conventional SMR, reaction products are usually sent to a PSA unit where hydrogen is separated from the remaining gases. The remaining stream still contains methane, hydrogen and carbon monoxide and is thus redirected to the furnace to raise heat for the endothermic reaction. This can also be done for the MR without the need for the PSA unit. However, if almost complete methane conversion and hydrogen recovery can be attained, the retentate stream will mainly consist of carbon dioxide and steam. Condensation of the steam leaves a concentrated $\mathrm{CO}_{2}$ stream at reaction pressure and would give the prospect of an inexpensive method for $\mathrm{CO}_{2}$ capture. Since $\mathrm{CO}_{2}$ is best transported in a supercritical state (80-100 bar [39]), the high exit pressure will also minimise compression energy. It should be emphasised that only capture of $\mathrm{CO}_{2}$ present in the retentate stream is economically viable. $\mathrm{CO}_{2}$ is also produced in the furnace, but the concentration in the flue gases is too low $(13 \%)$ to enable economic recovery at these scales.

According to two modelling studies [4,19], the retentate stream is almost $100 \% \mathrm{CO}_{2}$ after water removal. This can only be achieved using a counter-current sweep gas to dilute the hydrogen in the permeate stream [40]. If no sweep gas is utilised, approximately $5 \%$ of the hydrogen cannot be recovered [26] since a minimum partial pressure difference is required to force the hydrogen through the membrane. Other literature estimates report lower $\mathrm{CO}_{2}$ concentrations, but these do not use a sweep gas and have not been optimised for $\mathrm{CO}_{2}$ capture $[6,26,41]$.

In practice, even with a sweep gas it may not be feasible to obtain such high purity $\mathrm{CO}_{2}$, due to the optimal requirements of full methane conversion and hydrogen recovery [42,43]. To the author's knowledge no experimental results are available on the optimisation of the $\mathrm{MR}$ for $\mathrm{CO}_{2}$ capture. Due to this uncertainty, we consider two possibilities: either the $\mathrm{CO}_{2}$ is pure enough (after water removal) to enable direct transportation or significant levels of contaminants remain in the retentate stream and need to be removed prior to compression and transportation. In the latter case a separation technology is therefore necessary. Considering the scale of the system and the fact that the retentate stream has a relatively high $\mathrm{CO}_{2}$ partial pressure, cryogenic separation is the preferred technology according to two manufacturers of $\mathrm{CO}_{2}$ separation systems [44].

Cryogenic separation uses a freezing technique to capitalise on the difference between the freezing point of $\mathrm{CO}_{2}$ and other gases [45]. The process involves many different steps. First, the off-gas is cooled to about $30^{\circ} \mathrm{C}$ to condense most of the water, which is removed by a water-knock-out (KO) tank. The stream is then compressed to 35 bar and cooled to offset the heating of compression. More water is removed in a second tank, followed by a dehydration step to bring the water content to ppm levels. This is necessary to avoid corrosion and hydrate precipitation in pipelines further downstream [46]. In a refrigeration loop the $\mathrm{CO}_{2}$ is condensed at $-40{ }^{\circ} \mathrm{C}$ to remove most of the non-condensable gases such as $\mathrm{H}_{2}, \mathrm{CO}, \mathrm{CH}_{4}$ and $\mathrm{N}_{2}$ from the mixture. The off-gas can then be sent to the furnace for combustion. ${ }^{4}$ With this technology a $\mathrm{CO}_{2}$ recovery of $75-85 \%$ of the carbon dioxide present in the retentate gas can be achieved [47].

\section{Systems description}

Following the issues described in the previous section, several systems for the membrane reactor can be imagined. Previous studies (see e.g. $[4,6,12,19,20]$ ) have mainly considered two configurations, with or without the use of a sweep gas. Although the thermodynamic trade-off between the two configurations has been

\footnotetext{
${ }^{4}$ In practice, about $20 \%$ of the methane and $8 \%$ of the carbon monoxide present in the retentate stream cannot be separated and is lost [47]. This could be improved by further optimisation.
} 

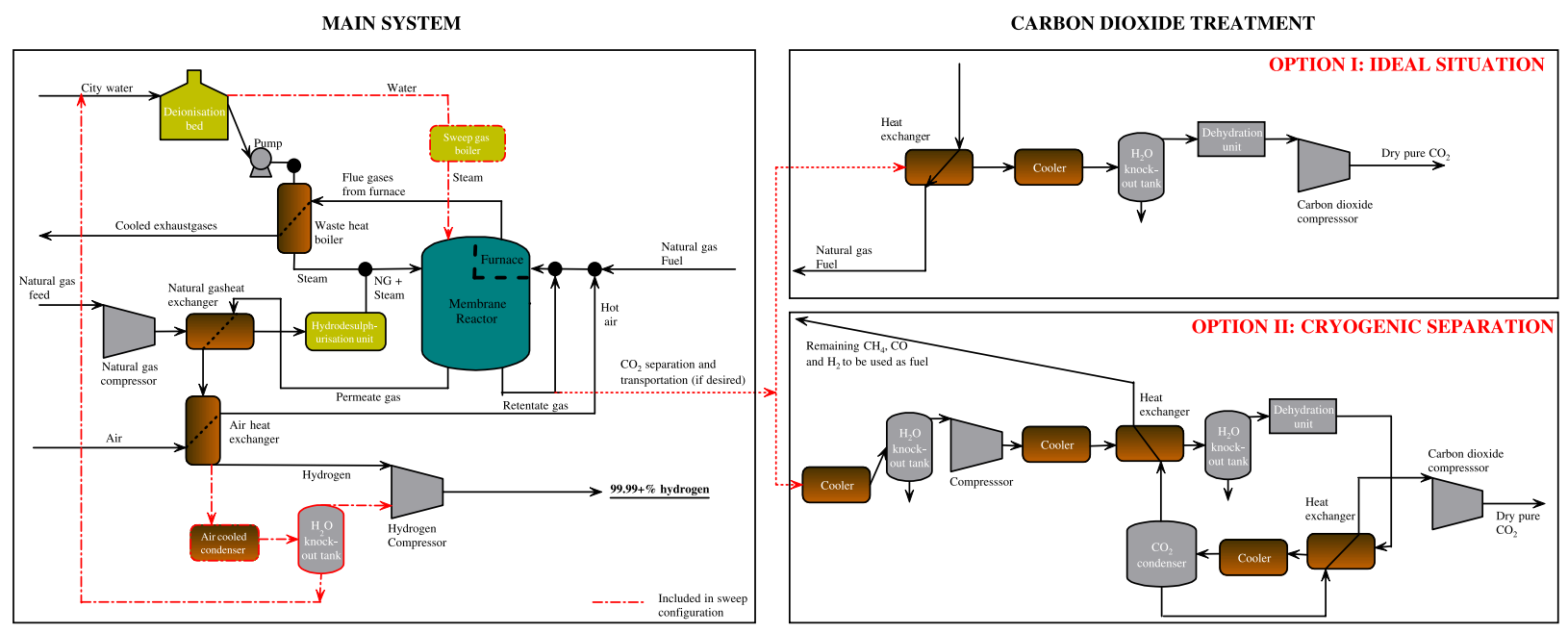

Fig. 4. Generic system flowsheet (include dotted lines and components for sweep configuration).

investigated, the economic trade-off has not been dealt with. In this study, both the non-sweep and sweep configurations are investigated. The retentate stream from the reformer is redirected to the furnace for heat production.

To evaluate the possibility of clean fossil fuel use for hydrogen production, i.e. continued consumption of fossil fuels with $\mathrm{CO}_{2}$ capture and sequestration, two additional configurations are studied. The first uses a sweep gas and immediately produces a pure $\mathrm{CO}_{2}$ stream ready for compression and transportation (ideal). The second is in principle the first configuration (non-sweep), but then supplemented by a cryogenic separation unit to purify the $\mathrm{CO}_{2}$ (non-ideal). Union Engineering, a manufacturer of $\mathrm{CO}_{2}$ separation units, has supplied us with a detailed flowsheet of a cryogenic unit specifically based on our situation. Their modelling approach is in accordance with our methodology and is therefore applicable to this study.

This leaves us with four configurations:

1. Non-sweep: MR without sweep gas;

2. Sweep: MR with sweep gas;

3. Non-ideal: MR without sweep gas and with cryogenic $\mathrm{CO}_{2}$ separation;

4. Ideal: MR with sweep gas and integrated $\mathrm{CO}_{2}$ capture.

Fig. 4 shows a representation of the system considered in this study. It is based on recent patents [48-50] and Myers et al. [24] and is specifically configured as a small-scale reformer at refuelling stations. We assume the configuration to be suitable for capacities of $0.2 \mathrm{MW}$ to several MW. ${ }^{5}$ For large-scale applications, a different configuration may be required.

Several aspects are specific for this configuration. The water is taken from the city water supply. Ions such as calcium and chloride present in the water need to be removed by a deionisation tank as they cause serious fouling and corrosion problems and can poison the catalysts [24]. Sulphur and sulphur compounds in the natural gas feed (for reforming) also poison the catalyst by chemically bonding to active sites and are therefore removed by a hydrodesulphurisation unit (HDS) coupled with a zinc-oxide bed. This step is not required when natural gas is used as fuel in the furnace. Gaseous hydrogen is considered for the system analysis as this currently appears to be the industry's preference [51]. The hydrogen is compressed to 482 bar to enable fast cascade-filling into vehicle tanks at 350 bar (see for a comprehensive explanation: Thomas et al. [52]).

\footnotetext{
${ }^{5}$ Unless stated otherwise, MW is based on the HHV of hydrogen produced.
} 


\section{Methodology and system assumptions}

\subsection{Thermodynamic modelling assumptions and model validation}

\subsubsection{General}

The selected configurations are modelled using the process simulation software Aspen ${ }^{\text {Plus }}$. Chemical equilibrium approximation is used for the calculations. An excess of highly active catalyst is generally used to guarantee that equilibrium is reached and that kinetic factors play a subordinate role in limiting the reaction [53-55]. For the MR the situation is different since hydrogen is simultaneously withdrawn from the reaction site. Adris et al. [7] have concluded that kinetic properties have limited influence for conditions studied in this article and other studies [37,54,56,57] have demonstrated that the removal of hydrogen through $\mathrm{Pd} / \mathrm{Ag}$ membranes is generally slow compared to the catalytic reaction rate (as long as no extremely thin membranes are used). Consequently, the gas composition near the membrane equals the gas composition in the catalytic bed $[53,54]$.

In our study, we have assumed an excess of catalyst to be available to ensure that equilibrium is reached. The computational effort can therefore be simplified as for kinetic calculations detailed knowledge is required on the reaction rate and its dependence on, e.g. temperature, activation energy and pressure. The kinetic properties of conventional steam reforming have been researched extensively, but to the authors' knowledge no study has yet investigated the precise impact of kinetics for the MR. The sources above suggest that the impact is not necessarily significant provided that the membrane is not too thin. It would therefore be interesting to study at which permeation rate and to what degree kinetics starts to significantly influence the reaction.

\subsubsection{Membrane reactor}

The membrane reactor is simulated with a short-cut method since no membrane reactor module is available in the Aspen unit models. A recycling loop is introduced to capture the intricate relationship between hydrogen removal and the shift in equilibrium. The hydrogen permeation is a complex function of the partial pressure difference across the membrane and is therefore modelled with a Fortran subroutine (see Eq. (1)). By assuming a certain permeability, membrane thickness and membrane area, the permeation rate can be calculated with an iterative procedure. This modelling approach does not capture the change in flux along the length of the membrane tube, the average flux is therefore approximated by the logarithmic mean of the flux at the inlet and outlet of the reactor, following [24]. ${ }^{6}$ This then determines methane conversion and hydrogen recovery.

\subsubsection{Model validation}

The modelling method is simple and does not represent the system in all its complexities. For the objective of our study, it is crucial that the most important output conditions (HR and MC) determining the economic viability of the technology are accurately calculated at specified input conditions (of which the most important are: driving force across the membrane, load to surface ratio and membrane permeability). Model validation is therefore done with the comprehensive mathematical model of Lin et al. [14]. With the same operating conditions, ${ }^{7}$ a MC of $71.4 \%$ and a HR of $68.5 \%$ are obtained. According to their extensive mathematical

\footnotetext{
${ }^{6}$ The driving force $\delta$ (see Eq. (1)) is then calculated with the following formula:

$$
\delta=\frac{\delta_{\text {in }}-\delta_{\text {out }}}{\ln \left(\delta_{\text {in }} / \delta_{\text {out }}\right)},
$$

where $\delta_{\text {in }}$ is the driving force at input end of tube $\left(\mathrm{Pa}^{0.5}\right)$ and $\delta_{\text {out }}$ the driving force at exit end $\left(\mathrm{Pa}^{0.5}\right) . \delta_{\text {in }}=\left(p_{\text {rin }}\right)^{0.5}-\left(p_{\text {pin }}\right)^{0.5}$ where $p_{\text {rin }}$ is the partial pressure on the retentate side at the input end $(\mathrm{Pa})$ and $p_{\text {pin }}$ the partial pressure on the permeate side at the input end $(\mathrm{Pa})$. $\delta_{\text {out }}=\left(p_{\text {out }}\right)^{0.5}-\left(p_{\text {out }}\right)^{0.5}$ where $p_{\text {out }}$ is the partial pressure on the retentate side at the exit end (Pa) and $p_{\text {pout }}$ the partial pressure on the permeate side at the exit end $(\mathrm{Pa})$.

${ }^{7}$ Load to surface ratio of $0.05 \mathrm{kmol} / \mathrm{h} \mathrm{m}^{2}$, permeability of $0.7 \mathrm{~mol} / \mathrm{m}^{2} \mathrm{~h} \mathrm{~Pa}{ }^{0.5}, 500{ }^{\circ} \mathrm{C}$, reaction pressure 20 bar and permeate pressure 1 bar.
} 


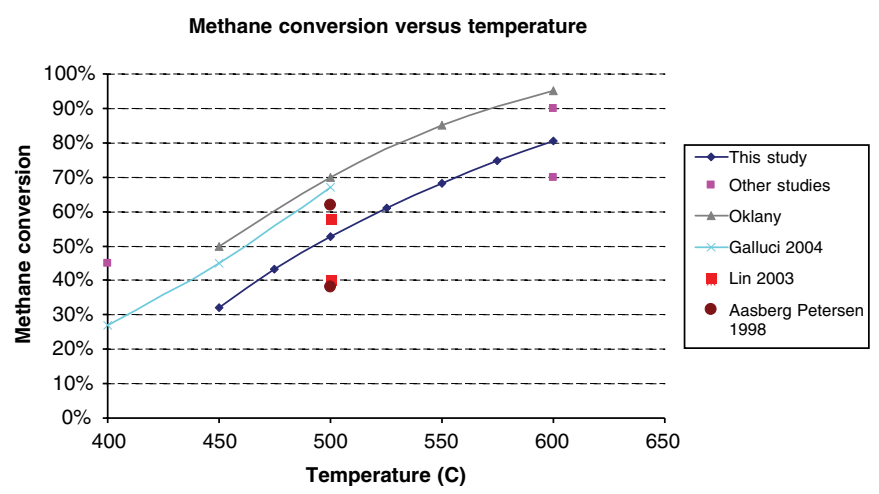

Fig. 5. Methane conversion dependence on temperature (other studies are: [12,13]).

model the results should be a MC of $70 \%$ and a HR of $68 \%$. These results indicate that methane conversion and hydrogen recovery are modelled correctly, possibly somewhat on the high side.

Since this comparison does not imply that the modelling is also done correctly under different conditions we have further verified the model by comparing our main results with those of more detailed modelling and experimental studies that have included kinetics and variation along the length of the reactor. It should be emphasised that it is difficult to make a detailed comparison with other studies as different assumptions have been made on membrane type, membrane permeability, retentate and permeate partial pressure, load to surface ratio, use of sweep gas, sweep gas flow rate, etc. Different assumptions for these variables can significantly change the main output conditions of the MR as shown in Fig. 5.

The values calculated by the model and the dependency of MC to temperature seem to coincide well with more detailed studies. The differences can mainly be explained by membrane permeability, use of a sweep gas and partial pressure difference between the two sides of the membrane. The temperature dependence is similar to that found by Oklany [12], but is lower due to the lower sweep to feed ratio. The model also shows a correct response to the effect of other operating conditions such as pressure and steam-to-carbon ratio (not shown).

In conclusion, the obtained values for methane conversion and hydrogen recovery for specified conditions are broadly in accordance with literature. This comparative analysis indicates that the modelling approach is sufficiently accurate for preliminary efficiency calculations and to assess the economic viability of the total system (see for example also the approach taken by Jordal in [58]). It should however be stressed that for an exact assessment of the thermodynamics of the MR and determining the optimal operating conditions for different configurations, more elaborate models are essential such as those already developed by, e.g. Adris et al. [7].

\subsubsection{Modelling assumptions}

All modelling assumptions are given in Table 1. The energy input to the system is minimised by utilising the heat of the output streams with several heat exchangers. The main intention is to select a realistic configuration in which most of the heat can be re-used without the cost for additional heat exchangers exceeding the cost savings of reduced fuel input. Heat recovery could be optimised with a pinch analysis, but that is beyond the scope of this study and in addition may give too ideal results.

\subsection{Economic assumptions ${ }^{8}$}

Results from the Aspen modelling are directly coupled to a spreadsheet model to evaluate the economics of the different concepts on the basis of cost data at component level. The methodology is similar to previous analyses conducted $[59,60]$. It should be noted that preliminary feasibility analyses such as these typically have an accuracy of $\pm 30 \%$ due to limited cost data and design detail [61]. The component cost figures as shown in Table 2 are obtained from literature sources, vendor quotes and personal communication with experts. Note

\footnotetext{
${ }^{8}$ All currencies in $\mathrm{US}_{2003}$.
} 
Table 1

Unit and stream modelling assumptions used in Aspen ${ }^{\text {Plus }}$ simulation $^{\text {a }}$

\section{General}

Heat exchangers

Water pump ${ }^{\mathrm{d}}$

Natural gas compressor

Hydrogen compressor

Carbon dioxide compressor

\section{Condenser}

Pre-treatment

HDS/Guard bed unit

\section{Reforming}

Reactor

Membrane

Furnace $^{\mathrm{p}}$

Purification

Water knock-out tank

Dehydration
$\Delta p / p=2 \%{ }^{\mathrm{b}}$

Minimum $\Delta T=15^{\circ} \mathrm{C}$ (gas-liquid) or $30^{\circ} \mathrm{C}$ (gas-gas) ${ }^{\mathrm{c}}$

Heat at temperatures lower than $100^{\circ} \mathrm{C}$ is not used

Centrifugal pump

$\eta=0.9, \eta_{\text {driver }}=1$

Multi-stage compressor with intercooling, 2-3 stages

Outlet temperature does not exceed $150^{\circ} \mathrm{C}^{\mathrm{e}}$

Maximum compression ratio is three

$\eta_{\text {polytropic }}=0.84^{\mathrm{f}}$

$\eta_{\text {mechanic }}=1$

Multi-stage compressor with intercooling, 9 stages

Maximum compression ratio is two ${ }^{\mathrm{g}}$

Outlet temperature does not exceed $135^{\circ} \mathrm{C}^{\mathrm{h}}$

Outlet pressure is 482 bar

$\eta_{\text {isentropic }}=0.78^{\mathrm{i}}$

$\eta_{\text {mechanic }}=1$

Multi-stage compressor with intercooling, 5 stages

Intercooling at $32{ }^{\circ} \mathrm{C}^{\mathrm{j}}$

Outlet pressure is $100 \mathrm{bar}$

$\eta_{\text {isentropic }}=0.78^{\mathrm{k}}$

$\eta_{\text {mechanic }}=1$

Air-cooled

Natural gas needs to be preheated to $380^{\circ} \mathrm{C}^{\mathrm{l}}$

Modelled as a valve for pressure drop ${ }^{\mathrm{m}}$

$\Delta p=1 \%{ }^{\mathrm{n}}$

Gibbs free energy minimisation reactor

Reactor operates at $T=500-600^{\circ} \mathrm{C}$

Pressure drop is modelled by valve in retentate stream, $\Delta p=-0.5$ bar $^{\circ}$

Steam-to-carbon ratio $=3$

Modelled as separator. Separates amount of hydrogen depending on permeation rate

Hydrogen at 1 bar

Membrane material $=\mathrm{Pd}_{23} \mathrm{Ag}$ with porous ceramic support

Membrane thickness $=20 \mu \mathrm{m}$

Permeability $=2.25 \mathrm{e}^{-5} \mathrm{~mol} \mathrm{~m} / \mathrm{m}^{2} \mathrm{~h} \mathrm{~Pa}^{0.5}$

Natural gas furnace provides heat for reaction, fuelled by retentate/purge gas. If this is not sufficient extra natural gas fuel is taken from the grid.

Modelled as stoichiometric reactor. $T=20^{\circ} \mathrm{C}$ more than $T$ reactor.

$\Delta p=-0.5$ bar

Fractional conversion $=100 \%$

No radiative heat loss

Twice the stoichiometric amount of air

Modelled as two outlet flash drum

$Q=0 \mathrm{~W}^{\mathrm{q}}$

$T_{\text {in }}=30^{\circ} \mathrm{C}^{\mathrm{r}}$

$\Delta p=-0.01$ bar $(1 \%)$

Over $99 \%$ of water is separated

Modelled as separator

$100 \%$ water removal 
Table 1 (continued)

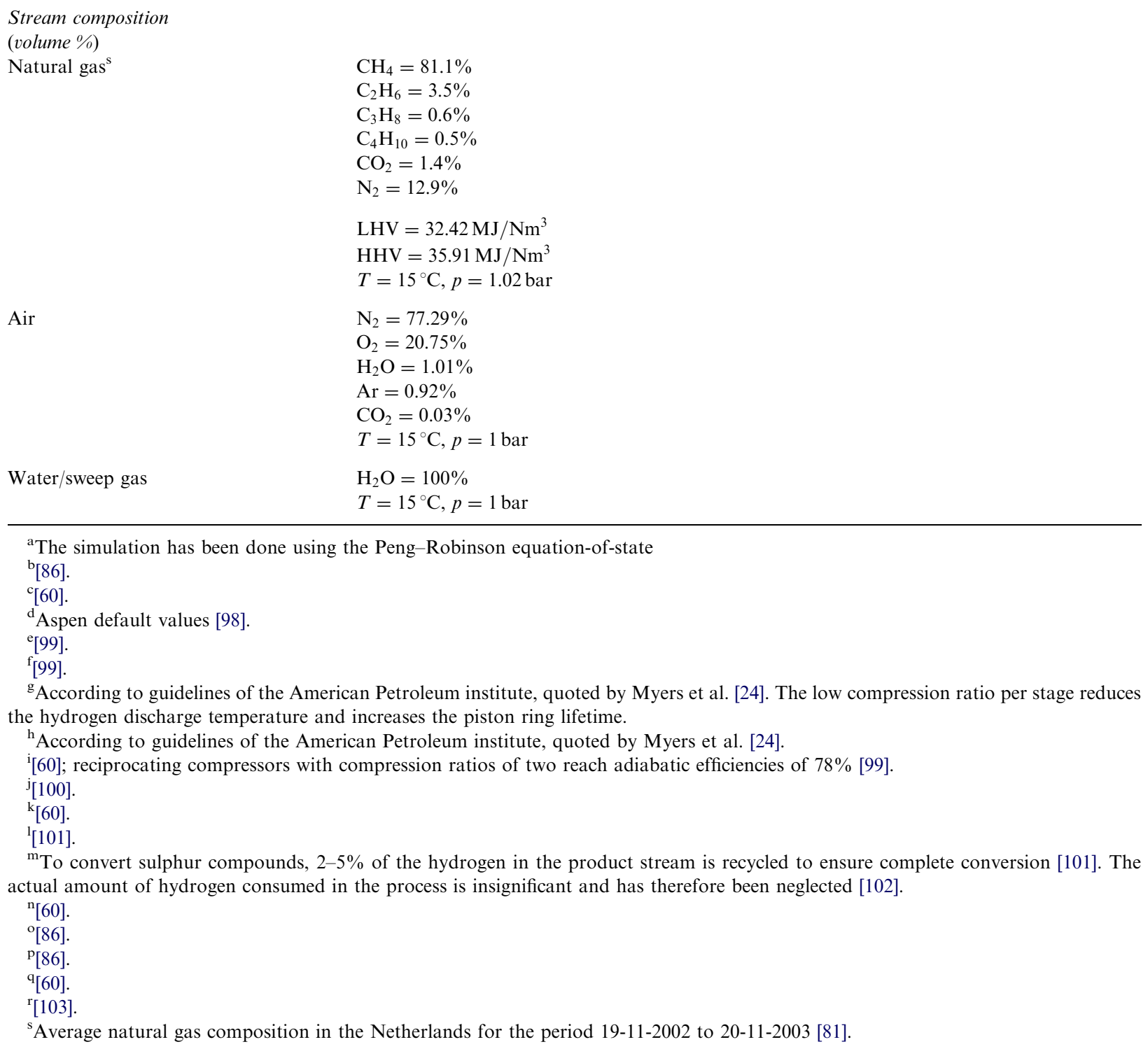

that these values are only valid for specific scales; to calculate the cost at other capacities (as derived from the Aspen modelling) it is common practice in engineering economics to make use of the following scaling equation $(R=$ scaling factor) [62]:

$$
\text { Cost }_{\text {new }}=\operatorname{Cost}_{\text {known }}\left(\frac{\text { Scale }_{\text {new }}}{\text { Scale }_{\text {known }}}\right)^{R} \text {. }
$$

The cost data are mainly derived from a detailed analysis recently conducted by Directed Technologies Inc. [24]. These have been generated for a small-scale steam reformer $(0.2 \mathrm{MW})$ according to the Design for Manufacturing and Assembly methodology (DFMA). This approach is extensively used by industry (e.g. Ford Motor Company) for product cost estimation and determines the total component cost using a bottom-up method based on material and manufacturing cost (see for a detailed explanation [24]). Component costs have been calculated for a production volume of 250 units. This is justified as (presuming a hydrogen economy 
Table 2

Capital cost of system components ${ }^{\mathrm{a}}$

\begin{tabular}{|c|c|c|c|}
\hline Component & Base investment cost $(000 \$)$ & Base scale & Scale factor \\
\hline \multicolumn{4}{|l|}{ Pre-reformer } \\
\hline Natural gas compressor & 3.3 & $5 \mathrm{~kW}$ & $0.82^{\mathrm{b}}$ \\
\hline Natural gas feed system & 0.2 & $5 \mathrm{~kW}$ & 0.82 \\
\hline Heat exchangers (steel) ${ }^{c}$ & 7.8 & $2 \mathrm{~m}^{2}$ & $0.59^{\mathrm{c}}$ \\
\hline $\begin{array}{l}\text { Heat exchangers (stainless- } \\
\text { steel) }\end{array}$ & 15.5 & $2 \mathrm{~m}^{2}$ & 0.59 \\
\hline Desulphurisation unit & 4.8 & $0.79 \mathrm{kmol} \mathrm{CH}_{4} / \mathrm{h}$ & $0.6^{\mathrm{b}}$ \\
\hline Water purification & 2.1 & $901 \mathrm{H}_{2} \mathrm{O} / \mathrm{h}$ & $0.68^{\mathrm{e}}$ \\
\hline Water pump & 1.2 & $901 \mathrm{H}_{2} \mathrm{O} / \mathrm{h}$ & $0.7^{\mathrm{f}}$ \\
\hline Waste-heat boiler & 19.2 & $901 \mathrm{H}_{2} \mathrm{O} / \mathrm{h}$ & 0.67 \\
\hline Sweep gas boiler & 19.2 & $901 \mathrm{H}_{2} \mathrm{O} / \mathrm{h}$ & 0.67 \\
\hline \multicolumn{4}{|l|}{ Reformer } \\
\hline Combustion chamber (furnace) & 2.1 & $4.79 \mathrm{~kg} \mathrm{H}_{2} / \mathrm{h}$ & $0.78^{\mathrm{g}}$ \\
\hline $\begin{array}{l}\text { Membrane reactor (without } \\
\text { membrane tubes) }\end{array}$ & 14.1 & $4.79 \mathrm{~kg} \mathrm{H}_{2} / \mathrm{h}$ & $0.7^{\mathrm{i}}$ \\
\hline \multicolumn{4}{|l|}{ Post-reformer } \\
\hline Hydrogen compressor & 22.0 & $4.79 \mathrm{~kg} \mathrm{H}_{2} / \mathrm{h}$ & 0.82 \\
\hline $\begin{array}{l}\text { Condenser and water knock } \\
\text { out }\end{array}$ & 4.9 & $4.79 \mathrm{~kg} \mathrm{H}_{2} / \mathrm{h}$ & 0.68 \\
\hline Carbon dioxide compressor $^{\mathrm{j}}$ & 3,000 & $6 \mathrm{MW}$ & 0.7 \\
\hline Dehydration equipment $\mathrm{t}^{\mathrm{k}}$ & 35.0 & $1180 \mathrm{~m}^{3} / \mathrm{h}$ & 0.7 \\
\hline Cryogenic $\mathrm{CO}_{2}$ separation unit ${ }^{1}$ & 475.0 & $0.6 \mathrm{tCO}_{2} / \mathrm{h}$ & 0.7 \\
\hline
\end{tabular}

\footnotetext{
${ }^{\mathrm{a}}$ If not indicated, values are taken from Myers et al. [24]; Values have been adjusted for inflation using the GDP Deflator Inflation Index.

${ }^{\mathrm{b}}[105]$.

' [106]; steel tube-shell heat exchanger.

${ }^{\mathrm{d}}[106]$; stainless steel tube-shell heat exchanger. If sweep gas is used, this type is required to prevent corrosion.

${ }^{\mathrm{e}}$ Average value for general and heat exchange equipment [105].

${ }^{\mathrm{f}}$ This is for a carbon steel positive displacement pump [105].

${ }^{\mathrm{g}}$ Average of the values $0.7-0.85$, quoted from different sources by Remer et al. [105].

${ }^{\mathrm{h}}$ This includes the reactor core itself, the inlet and outlet headers and the assembly of the reactor. Additional expenditure to prevent the negative effect of thermal cycling has not been taken into account. SS316 is used instead of Haynes556.

i[105]; this is only for reactors in general, not specifically for the membrane reactor. Average of the values $0.65-0.74$.

${ }^{\mathrm{j}}$ Atlas Copco [107].

${ }^{\mathrm{k}}$ Taken from [108]; capital cost data are for a dehydration unit operating at 31 bar and $10^{\circ} \mathrm{C}$. Cost for the glycol unit is $\$ 20,000$; increased with $75 \%$ to account for installation and engineering.

${ }^{1}$ Cost estimate from Union Engineering [47] is \$ 450,000-500,000 for specifically this system; the average was taken. This represents installed cost.
}

becomes a reality) many small-scale reformers will be necessary to meet demand ${ }^{9}$ and it is expected that they will be pre-assembled at a production plant. These values only represent the free on board (FOB) cost. Hence, for total investment expenditure of a refuelling station, additional costs are required for system assembly at the production plant and for installation at the refuelling station (on-site) (see Table 3). These fractions are mainly taken from the above-mentioned study for small-scale reformers [24].

Due to the experimental status of the MR no cost estimates were found for the membrane reformer itself. It is assumed that the basic reactor configuration resembles a normal SMR, but since operating temperature is lower less expensive materials can be used. For example, an SMR requires high-quality steel alloys such as Haynes 556 [24], whereas the MR can suffice with stainless steel types such as 304 or 316 SS [64], which cost a factor ten less [65]. The membrane tubes are an additional cost factor, which is dependent on membrane

\footnotetext{
${ }^{9}$ To put these figures in perspective: the Netherlands currently has about 4150 refuelling stations [63].
} 
Table 3

Installation factors

\begin{tabular}{ll}
\hline Total facilities cost & TFC \\
\hline Instrumentation and control & $13 \%$ \\
Structural support & $5 \%$ \\
Assembly & $5 \%$ \\
Piping & $2 \%$ \\
Total system assembly & \\
Total plant cost (TPC) & $25 \%$ \\
Site preparation & 1.25 TFC \\
Assembly on-site & $0.5 \%$ \\
Tax, insurance and freight & $10 \%$ \\
Engineering & $2 \%$ \\
Contingency & $5 \%$ \\
Fees, overhead and profit & $10 \%$ \\
Start-up cost & $10 \%$ \\
Total installation & $5 \%$ \\
Total capex & $42.5 \%$ \\
\hline
\end{tabular}

${ }^{\text {a }}$ These figures are based on Myers et al. [24], but instead of the actual cost, the percentage of the PFC is taken to enable calculation at different capacities.

${ }^{\mathrm{b}}$ Based on Perry et al. [104] and Myers et al. [24].

surface, raw material price and production cost. Johnson Matthey, one of the leading producers of palladium membrane tubes, have stated that at current prices raw material constitutes $40 \%$ and tube manufacturing $60 \%$ of total production $\operatorname{cost}^{10}$ [34]. The exact cost of tube production also depends on the type of support. A porous metallic support is more expensive than ceramic, but has the advantage of simple connections and easy noticeable cracks. According to expert knowledge, our assumption is on the high side of costs for ceramic support (including intermediate layers) and slightly on the low side for metallic support [66]. Production cost could be significantly reduced when machine assembly becomes an option.

The annual investment cost is calculated by multiplying the total Capex with an annuity factor. ${ }^{11}$ The economic parameters used are given in Table 4. Other costs such as raw materials and utilities form the annual operational expenditure. It is assumed that besides maintenance tasks the reformer can operate unattended and labour costs can therefore be omitted. Property taxes, insurance and O\&M are taken as a percentage of the total installed investment. Electricity and natural gas prices supplied from the grid are based on prices for small industrial users in the EU according to the annual natural gas and electricity consumption of the reformer [67].

Other operational expenditure consists of the cost to replace catalysts, deionisation bed resin, $\mathrm{ZnO}$ adsorbent and membrane tubes. The cost of membrane tube replacement is a rather uncertain factor. Demonstration projects have shown lifetimes ranging from several thousand hours [68] up to more than 15 months [69] after which the membrane was rendered unusable. This was caused by leaks in the membrane due to insufficient mechanical stability. It is expected that long-term performance stability will be improved considerably. As we are concerned with a medium-term estimate, we follow the economic feasibility analysis of Criscuoli et al. [18] and assume a membrane lifetime of 3 years $(21,000 \mathrm{~h}$ operation). The membrane material

\footnotetext{
${ }^{10}$ Membrane tube cost are thus calculated by multiplying the required surface area with raw material cost and then multiplied by a factor 2.5 to account for tube manufacturing (1.5 raw material cost).

$$
\alpha=\frac{d}{1-1 /(1+d)^{n}}
$$

with $d=r+i+\operatorname{ir}(\alpha=$ annuity factor, $d=$ after tax rate of return, $r=$ after tax real rate of return, $i=$ inflation, $n=$ lifetime).
} 
Table 4

Cost parameters

\begin{tabular}{ll}
\hline Investment & \\
Lifetime & $15 \mathrm{yrs}$ \\
After-tax real rate of return & $10 \%$ \\
Inflation rate & $2 \%$ \\
Annuity factor & $15.27 \%$ \\
Operational expenditure & \\
Annual load & $80 \%$ \\
O\&M & $4 \%$ \\
Property taxes & $2 \%$ \\
Insurance & $1.5 \%$ \\
Natural gas price & $4.18 \$ / \mathrm{GJ}$ \\
Electricity price & $0.07 \$ / \mathrm{kWh}$ \\
Palladium price & $6752 \$ / \mathrm{kg}$ \\
Silver price & $203 \$ / \mathrm{kg}$ \\
Water price & $0.282 \$ / \mathrm{m}^{3}$ \\
Replacements & \\
Hydrodesulphurisation catalyst & \\
Zinc-oxide adsorbent & $35.8 \$ / 1$ \\
Deionisation-bed resin & $16.6 \$ / 1$ \\
Reforming catalyst & $1500 \$ / \mathrm{yr}$ \\
\end{tabular}

itself is not modified by operation and can therefore be recycled (already done by MRT [69]). When replacing the membrane tubes we assume it is feasible to recover $60 \%$ of the palladium ${ }^{12}$ [70] and we assume the costs to be negligible [64]. As a comparison, the average recycling efficiency of palladium and platinum in the chemical and petrochemical industry is $76 \%$ [71].

\subsection{Optimal process conditions}

Since many parameters affect the thermodynamic and economic performance of the MR, an extensive analysis is performed to determine the most favourable conditions at which the MR should operate. For the aim of our study, we are mainly concerned with the most economically viable option. The optimal conditions are therefore those with the lowest hydrogen production cost and consequently do not have to coincide with the best thermodynamic conditions.

As the Aspen results are directly coupled to a spreadsheet calculating the economics, the effect of a change in process conditions on the hydrogen production cost can immediately be evaluated. By changing one parameter at a time, the conditions at which the hydrogen cost is lowest can be determined. Table 5 shows the range of values that is investigated in this study. In the case of the ideal configuration with integrated $\mathrm{CO}_{2}$ separation, the optimal conditions not only need to ensure the production of hydrogen at lowest cost, but also need to comply with the fact that the retentate stream should contain as little contaminants as possible.

\section{System calculation results}

\subsection{Results optimal process conditions}

The process parameters with the lowest hydrogen production cost are shown in Table 6 for all configurations. Although the conditions correspond well to other experimental and modelling studies ${ }^{13}$ (as explained in Section 2.3) there could be small variations due to the specific modelling method and

\footnotetext{
${ }^{12}$ Confidential data showed that spent material can be sold back to the market at competitive prices.

${ }^{13}[21,12,4,72,16,14,13,73,8,74,6,75,35,56,38,76,32,77,15,7,19]$.
} 
Table 5

Range of operating conditions investigated in this study

\begin{tabular}{ll}
\hline Process conditions & Investigated range $^{\mathrm{a}}$ \\
\hline Temperature (Celcius) & $475-600$ \\
Pressure (bar) & $2.5-60$ \\
Steam/carbon ratio (dimensionless) & $2.5-3.5$ \\
Load/surface ratio (kmol/ $\mathrm{h} \mathrm{m}^{2}$ ) & $0.03-0.50$ \\
Sweep gas ratio (dimensionless) & $0.25-5$ \\
\hline
\end{tabular}

\footnotetext{
${ }^{a}$ Derived from literature values: [4,6-8,12-16,19,21,32,35,38,56,72-77]. The possible negative influence of operating at a slightly higher temperature and higher pressure such as faster membrane degradation and possibly the use of different materials has not been taken into account.
}

Table 6

Optimal conditions for the membrane reactor

\begin{tabular}{|c|c|c|c|}
\hline \multirow[t]{2}{*}{ Process conditions } & \multicolumn{3}{|c|}{ Optimal conditions } \\
\hline & Sweep & Non-sweep/non-ideal & Ideal \\
\hline Temperature (Celcius) & 550 & 575 & 600 \\
\hline Pressure (bar) & 15 & 25 & 25 \\
\hline Steam/carbon ratio (dimensionless) & 3 & 3 & 3 \\
\hline Load/surface ratio $\left(\mathrm{kmol} / \mathrm{h} \mathrm{m}^{2}\right)$ & 0.083 & 0.094 & 0.083 \\
\hline Sweep gas ratio (dimensionless) & 0.5 & - & 0.5 \\
\hline \multicolumn{4}{|l|}{ Retentate gas $(\% \mathrm{~mol})$} \\
\hline $\mathrm{CH}_{4}$ & $3.2 \%$ & $4.5 \%$ & $3.6 \mathrm{e}-4 \%$ \\
\hline $\mathrm{H}_{2}$ & $6.3 \%$ & $6.6 \%$ & $1.0 \%$ \\
\hline $\mathrm{H}_{2} \mathrm{O}$ & $39.1 \%$ & $40.7 \%$ & $35.6 \%$ \\
\hline $\mathrm{CO}_{2}$ & $42.8 \%$ & $39.6 \%$ & $55.0 \%$ \\
\hline $\mathrm{CO}$ & $1.9 \%$ & $2.1 \%$ & $0.6 \%$ \\
\hline $\mathrm{N}_{2}$ & $6.6 \%$ & $6.4 \%$ & $7.8 \%$ \\
\hline
\end{tabular}

assumptions. Differences in the latter are caused by local conditions such as natural gas and electricity prices, specific configurations chosen related to heat production, heat transfer, reformer geometry or membrane deterioration. The optimal conditions for the non-ideal configuration are equal to those for the non-sweep since these give the lowest overall hydrogen production cost and a high purity retentate stream is not required due to the cryogenic $\mathrm{CO}_{2}$ separation unit.

As expected, the sweep configuration can operate at lower temperatures and lower pressures than the nonsweep and ideal configuration since the driving force across the membrane is increased by the sweep flow. A higher sweep gas ratio than the optimum (0.5) results in higher hydrogen recoveries and methane conversion, but this does not outweigh the higher cost of steam generation and water removal. This is also the case for the configuration with integrated $\mathrm{CO}_{2}$ capture (ideal) in which a higher temperature and a higher pressure is more economic than an increase in the sweep flow rate.

Table 6 also shows the retentate gas composition for the selected systems. The modelling results for the ideal configuration confirm the high purity of $\mathrm{CO}_{2}$ in the retentate gas. The high nitrogen concentration is a direct consequence of the high nitrogen content of Dutch natural gas. It is expected that this does not pose any problems as the mixture of natural gas and nitrogen is already distributed in pipelines. The latter argument also applies to the small methane and CO concentration. In contrast, hydrogen has negative implications as it results in pipeline embrittlement. Research has recently been conducted into the effect of a methane/hydrogen mixture on natural gas pipelines and preliminary results have shown that a concentration of up to $3 \mathrm{vol} \%$ is possible without any additional investment in the network [78]. Taking these issues into account, we can conclude that it is very likely that the retentate stream can be immediately transported. 
Table 7

Thermodynamic performance of the membrane reactor

\begin{tabular}{|c|c|c|c|c|c|}
\hline & \multirow[t]{2}{*}{ Literature range } & \multicolumn{4}{|l|}{ Results } \\
\hline & & Non-sweep & Sweep & Non-ideal & Ideal \\
\hline Methane conversion (MC) & $45-99 \%{ }^{\mathrm{a}}$ & $88.7 \%$ & $92.2 \%$ & $88.7 \%$ & $99.9 \%$ \\
\hline Hydrogen recovery (HR) & $70-99 \%$ & $95.8 \%$ & $96.3 \%$ & $95.8 \%$ & $99.0 \%$ \\
\hline \multicolumn{6}{|l|}{ Mass balance $(\mathrm{kmol} / \mathrm{h})$} \\
\hline Natural gas feed & - & 8.2 & 7.8 & 8.2 & 7.1 \\
\hline Natural gas fuel & - & 1.6 & 1.7 & 1.6 & 2.8 \\
\hline Water & - & 20.0 & 16.1 & 20.0 & 14.6 \\
\hline Air & - & 53.7 & 48.2 & 53.7 & 56.4 \\
\hline Hydrogen produced & - & 25.2 & 25.2 & 25.2 & 25.2 \\
\hline Retentate gas & - & 16.5 & 15.3 & 16.5 & 12.2 \\
\hline Exhaust gas & - & 71.2 & 64.6 & 71.2 & 59.3 \\
\hline \multicolumn{6}{|l|}{ Energy balance } \\
\hline Total HHV efficiency & $70-82 \%{ }^{b}$ & $77.8 \%$ & $77.3 \%$ & $76.5 \%$ & $76.9 \%$ \\
\hline Total HHV efficiency — primary energy ${ }^{c}$ & - & $70.5 \%$ & $70.3 \%$ & $68.1 \%$ & $69.6 \%$ \\
\hline \multicolumn{6}{|l|}{ Internal energy use } \\
\hline Fuel use in furnace $\left(\mathrm{GJ}_{\text {fuel }} / \mathrm{GJ}_{\mathrm{H}_{2}}\right)$ & - & 0.20 & 0.20 & 0.20 & 0.33 \\
\hline Electricity use $\left(\mathrm{GJ}_{\mathrm{el}} / \mathrm{GJ}_{\mathrm{H}_{2}}\right)$ & - & 0.11 & 0.11 & 0.13 & 0.11 \\
\hline Electricity use primary $\left(\mathrm{GJ}_{\text {elp }} / \mathrm{GJ}_{\mathrm{H}_{2}}\right)$ & & 0.24 & 0.24 & 0.29 & 0.24 \\
\hline
\end{tabular}

${ }^{\mathrm{a}}[6,12-14,16,20,40,79,109-112]$.

b $[11,79]$; without hydrogen compression.

${ }^{c}$ Electricity input calculated as primary energy using an efficiency of the grid of $45 \%$ [94].

For a $2 \mathrm{MW}$ hydrogen production plant, the amount of $\mathrm{CO}_{2}$ in the exhaust gas is approximately $2.68 \mathrm{kmol} /$ $\mathrm{h}$ compared to $6.45 \mathrm{kmol} / \mathrm{h}$ in the retentate stream. This means that a mere $71 \%$ of the carbon dioxide produced in the process can be recovered for sequestration purposes. Moreover, recovery efficiency with separation technologies is only about $80-90 \%$ and therefore, assuming $80 \%$ recovery, only $57 \%$ of the total $\mathrm{CO}_{2}$ produced in the process can be captured.

\subsection{Thermodynamic performance}

Table 7 summarises the thermodynamic performance of the MR. The figures are equal for the capacity range studied $(0.2-10 \mathrm{MW})$ as nothing is assumed to change in the configuration (although heat losses may be lower and compression more efficient at larger scales). The obtained results of around $89-92 \%$ methane conversion and $96 \%$ hydrogen recovery ${ }^{14}$ are on the high-end of values given in literature. A total efficiency ${ }^{15}$ of about $77.5 \%$ (HHV) for the configurations without $\mathrm{CO}_{2}$ capture can be attained. Practical results with the MR are obtained from Membrane Reactor Technologies, 82\% HHV [11] and Tokyo Gas Company, 70\% [79]. The efficiency value of MRT includes hydrogen compression, which compares to $81.6 \%$ for the modelled MR with the same compression requirement, almost equal to the value given by MRT. The efficiency of a conventional SMR (without $\mathrm{H}_{2}$ compression) is in the range of $75-80 \%[24,80]$. The total efficiency of the MR without any hydrogen compression, $83.9 \%$, is thus higher than conventional technology.

The total efficiency for the sweep configuration is $0.5 \% \mathrm{pt}$ lower than non-sweep. The additional energy required for steam generation is thus not completely compensated by the higher $\mathrm{MC}$ and the lower temperature and pressure at which the system operates. For the ideal configuration, the efficiency loss is due to

\footnotetext{
${ }^{14}$ The HR mentioned here is higher than in Section 4, because of different definitions (see Section 2.1 for the definition applied to results in this article).

${ }^{15}$ Defined as hydrogen energy output divided by energy input (fuel, feed and electricity).
} 
the different conditions at which the reactor needs to operate, $0.2 \%$ pt and $\mathrm{CO}_{2}$ compression, $0.3 \%$ pt. For the cryogenic option, no adjustment is required for the configuration, but efficiency loss is a consequence of the electricity needed for cooling, pumping and compression.

Efficiency increase could be established in a number of ways. Firstly, optimising heat flows can induce a small improvement. Secondly, by improving the compressor performance $(10 \%$ less electricity consumption results in a $0.5 \%$ pt efficiency increase). This will not be substantial as assumed performance is already optimistic and no significant advances are expected in the medium future. Thirdly, natural gas supplied at 16 bar $^{16}$ instead of 1.02 bar reduces compressor power such that total efficiency is raised with $1 \%$ pt. Fourthly, efficiency improvements could be realised by a higher membrane flux and larger membrane surface. The first can be achieved by higher permeability and is thus mainly dependent on further advances in membrane technology, but membrane assumptions are quite optimistic so significant improvement is not expected. Larger membrane surface would also cause an efficiency increase, but this would obviously have a negative impact on hydrogen production cost.

\subsection{Economic performance}

Results of the economic evaluation of a $2 \mathrm{MW}$ capacity membrane reactor are given in Table 8 for all systems studied. This capacity represents the volume of hydrogen that would be required for a future hydrogen refuelling station. ${ }^{17}$

The results clearly illustrate that the capital expenditure for the different concepts increases as system complexity becomes greater. The non-ideal configuration is almost $30 \%$ more expensive than the non-sweep. The same holds for the annual cost, albeit in a lesser extent. The final hydrogen cost for the sweep configuration is slightly higher, $14.1 \$ / G J$ compared to $13.5 \$ / G J$, illustrating that lower temperature and pressure do not outweigh extra costs related to the operation of a sweep gas.

When $\mathrm{CO}_{2}$ capture is included, the hydrogen cost increases to 13.9 and $15.5 \$ / \mathrm{GJ}$ for the ideal and non-ideal situation, respectively. Thus, the constraint of high purity $\mathrm{CO}_{2}$ adds only $4 \%$ to the hydrogen cost in the ideal situation and $14 \%$ in the case of a separation unit. If the hydrogen production cost is required to remain the same as for the non-sweep configuration (cheapest option), cost per tonne of $\mathrm{CO}_{2}$ separated can be calculated. For the ideal configuration this is $14 \$ / \mathrm{t} \mathrm{CO}$, three times less than with cryogenic separation, $49 \$ / \mathrm{CO}_{2}$, and less than separation cost for large-scale $(1000 \mathrm{MW})$ steam reformers: $21 \$ / \mathrm{t} \mathrm{CO}_{2}$ [84].

As illustrated by Fig. 6, mainly the reformer (including membrane tubes) and hydrogen compressor determine total capital cost and therefore a large part of the final hydrogen cost since capital recovery is responsible for about $22 \%$ of annual cost. The initial membrane tubes account for over one-third of capital expenditure and their replacement for $8 \%$ of annual cost. A cost reduction in membrane raw material or tube production can therefore have a significant effect on the final hydrogen cost. Obviously, natural gas and electricity consumption also influence cost noticeably, $34 \%$ (7\% fuel and $27 \%$ feed) and 18\%, respectively.

\subsubsection{Technological learning}

The capital cost of the membrane reactor could decline in the future due to technological learning. The effect of technological learning is commonly represented by experience curves, ${ }^{18}$ which describe how capital costs decline with cumulative production. The learning rate (LR) is the characteristic parameter, describing the percentage reduction in unit price with every doubling of cumulative production. The cost reduction is a result of factors including: economies of scale due to upscaling of units (upscaling), economies of scale due to the

\footnotetext{
${ }^{16}$ The pressure of the grid to which many industrial users are connected [81].

${ }^{17}$ According to the number of cars in the Netherlands: 7.7 million and the number of refuelling stations: 4153 [63], 1856 cars are supported by an average refuelling station. Assuming an annual travel distance per car of $16,100 \mathrm{~km} / \mathrm{yr}$ [63], annual operation of $80 \%$ and fuel economy of $0.98 \mathrm{~km} / \mathrm{MJ} \mathrm{H}_{2}(\mathrm{HHV})$ ( $=80 \mathrm{mpge}$ ) [24], a production of $1.2 \mathrm{MW}$ hydrogen would be required. Currently, only a fuel economy of $0.55 \mathrm{~km} / \mathrm{MJ}$ has been achieved for fuel cell vehicles [82], which would require a production of $2.2 \mathrm{MW}$ of hydrogen. Other studies have used capacities of up to $4 \mathrm{MW}$ [83], mainly focussed on the US. Considering these different values we assume $2 \mathrm{MW}$ as an intermediate capacity.

${ }^{18} \mathrm{An}$ experience curve is generally described as $C_{\text {cum }}=C_{0} \mathrm{CUM}^{\mathrm{b}}$ where $C_{\text {cum }}$ is the cost per unit, $C_{0}$ the initial cost of unit, CUM the cumulative production over time and $\mathrm{b}$ is the experience index. The learning rate is defined as $1-2^{\mathrm{b}}[85]$.
} 
Table 8

Economic analysis for the systems considered (capacity of $2 \mathrm{MW}$ )

\begin{tabular}{|c|c|c|c|c|}
\hline$(000 \$)$ & Non-sweep & Sweep & Non-ideal & Ideal \\
\hline \multicolumn{5}{|l|}{ Capital expenditure (capex) } \\
\hline Membrane tubes & 232 & 251 & 232 & 235 \\
\hline Reformer vessel & 89 & 89 & 89 & 89 \\
\hline Combustion chamber & 14 & 14 & 14 & 14 \\
\hline NG feed system & 1 & 1 & 1 & 1 \\
\hline NG compressor & 16 & 11 & 16 & 12 \\
\hline NG heater & 2 & 4 & 2 & 3 \\
\hline Air heater & 6 & 13 & 6 & 12 \\
\hline Boiler & 48 & 47 & 48 & 44 \\
\hline Desulphurisation unit & 19 & 19 & 19 & 18 \\
\hline Water purification & 5 & 3 & 5 & 5 \\
\hline Water pump & 3 & 3 & 3 & 3 \\
\hline Condenser/water knock-out & - & 25 & - & 25 \\
\hline Condenser/water knock-out & - & - & - & 7 \\
\hline Hydrogen compressor & 152 & 153 & 152 & 153 \\
\hline Sweep boiler & - & 17 & - & 16 \\
\hline Dehydration equipment & - & - & - & 1 \\
\hline $\mathrm{CO}_{2}$ compressor & - & - & - & 16 \\
\hline Additional heat exchangers & - & - & - & 5 \\
\hline Cryogenic separation unit & - & - & 164 & - \\
\hline Total facilities cost (TFC) & 587 & 648 & 751 & 657 \\
\hline Total plant cost $(T P C)$ & 734 & 810 & 939 & 821 \\
\hline Total capex & 1,046 & 1,155 & 1,338 & 1,170 \\
\hline \multicolumn{5}{|l|}{ Annual cost } \\
\hline O\&M & 42 & 46 & 54 & 47 \\
\hline Methane fuel & 42 & 56 & 42 & 72 \\
\hline Methane feed & 203 & 194 & 203 & 176 \\
\hline Electricity & 107 & 104 & 129 & 110 \\
\hline Water & 1 & $<1$ & 12 & 1 \\
\hline HDS catalyst replacement & 10 & 10 & 10 & 9 \\
\hline Resin replacement & 15 & 14 & 15 & 13 \\
\hline Membrane replacement & 59 & 64 & 59 & 60 \\
\hline Reforming catalyst & 5 & 5 & 5 & 5 \\
\hline Annual insurance and tax & 37 & 40 & 47 & 41 \\
\hline Annual capital cost & 162 & 179 & 207 & 181 \\
\hline Total annual cost & 683 & 712 & 782 & 714 \\
\hline \multicolumn{5}{|l|}{ Hydrogen cost } \\
\hline$\$ / \mathrm{kg}$ & 1.9 & 2.0 & 2.2 & 2.0 \\
\hline \$/GJ (HHV) & 13.5 & 14.1 & 15.5 & 13.9 \\
\hline $\mathrm{CO}_{2}$ cost $\left(\$ / \mathrm{t} \mathrm{CO}_{2}\right.$ separated $)$ & - & - & 49 & 14 \\
\hline
\end{tabular}

production of more identical units at one plant (mass production), process improvements, learning-by-doing, and reduction in raw material costs [85].

Fig. 7 shows the effect of system upscaling on hydrogen cost as determined by the Aspen study. Although a reduction is certainly present, the effect of upscaling is less than for conventional reforming owing to the modular nature of the MR. If the scaling equation is used (see Section 4.2) to calculate capital cost for other sizes, a scaling factor of 0.85 is obtained for the total system. ${ }^{19}$ The configuration studied is for small-scale, but it is uncertain up to which capacity this scaling factor is applicable.

\footnotetext{
${ }^{19}$ Compare this to scaling factors for SMR commonly used in literature: $0.6[60]$ and $0.7[86]$.
} 


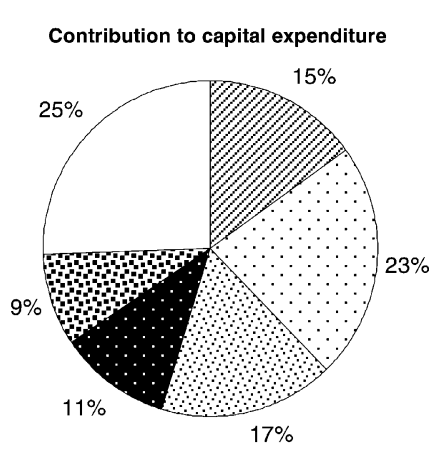

$\measuredangle$ Membrane material $\checkmark$ Membrane reformer

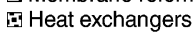

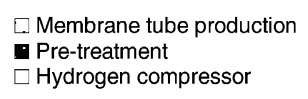

- Pre-treatment

$\square$ Hydrogen compressor

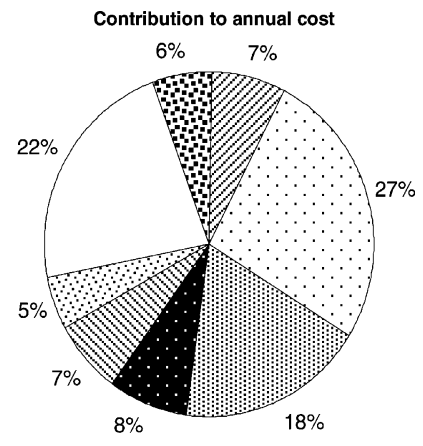

G O\&M

$\square$ Natural gas feed

- Membrane replacement

Annual insurance and tax $\triangle$ Natural gas fuel

Electricity

Catalysts/other replacements

$\square$ Annual capital cost

Fig. 6. Contribution to capital expenditure and annual cost (2 MW non-sweep).
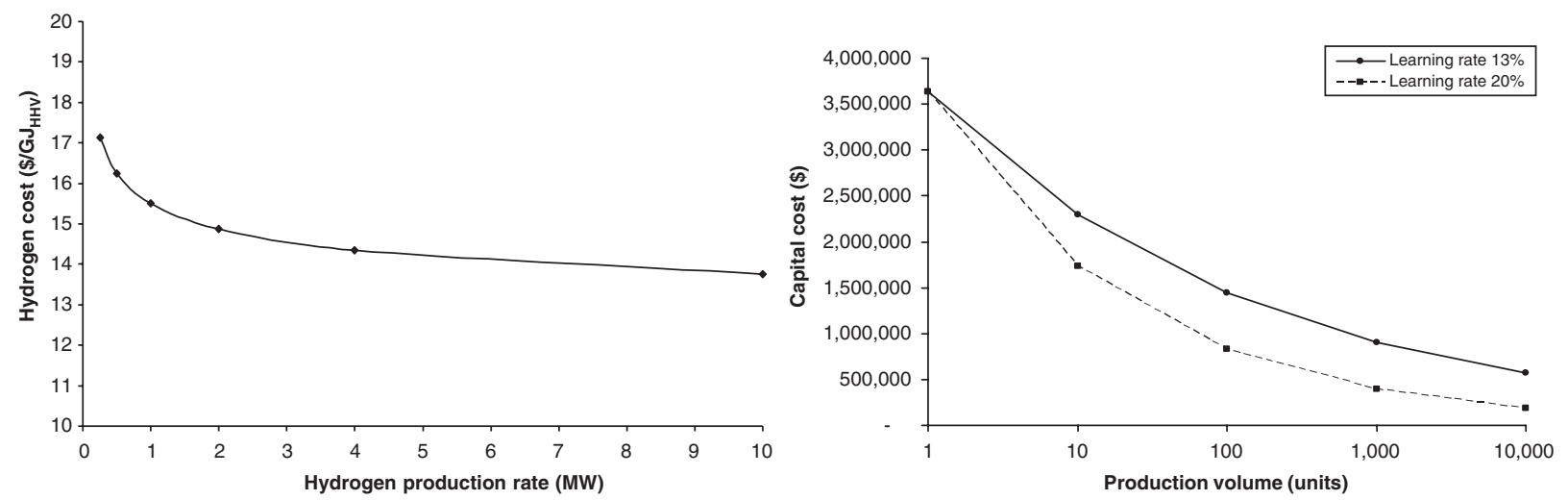

Fig. 7. Effect of upscaling (left) and technological learning (right) of the MR (2 MW non-sweep).

To a certain extent, the effect of mass production is already incorporated in the prices since a production volume of 250 units is assumed. However, given that the technology is in an early stage of development, process improvement and learning-by-doing play a significant role as well. If these effects are included we can construct an experience curve as illustrated in Fig. 7, using two learning rates: $13 \%$ and $20 \%$. The first is representative for technologies such as wind turbines [87], whilst the latter is more applicable to modular systems such as PV solar panels [88]. No LR is available on hydrogen reforming technologies and it is therefore uncertain which would be most appropriate. Since the hydrogen reformer market can be regarded as a global market, cumulative production corresponds to global production. Considering that there are more than 4000 refuelling stations in the Netherlands alone, even with a low LR the potential exists for significant cost reductions (i.e. assuming hydrogen takes off as a transportation fuel). For instance, with a LR of $13 \%$ and only two doublings of cumulative production (250-1000), hydrogen cost can be reduced with $9 \%$ to $13 \$ /$ GJ (2 MW non-sweep). One should note that this reduction is also possible for conventional technology, but as the technology is already more advanced the learning rate is less and further doublings require a larger market.

\subsubsection{Comparison with $S M R$}

The economic results cannot be compared to other estimates as almost none are available. Preliminary analyses of an MR have been reported by Aasberg-Petersen et al. [21], Roy et al. [20] and Middleton et al. [19], but these are unspecific and only consider large-scale membrane reformers and are therefore unsuitable for 


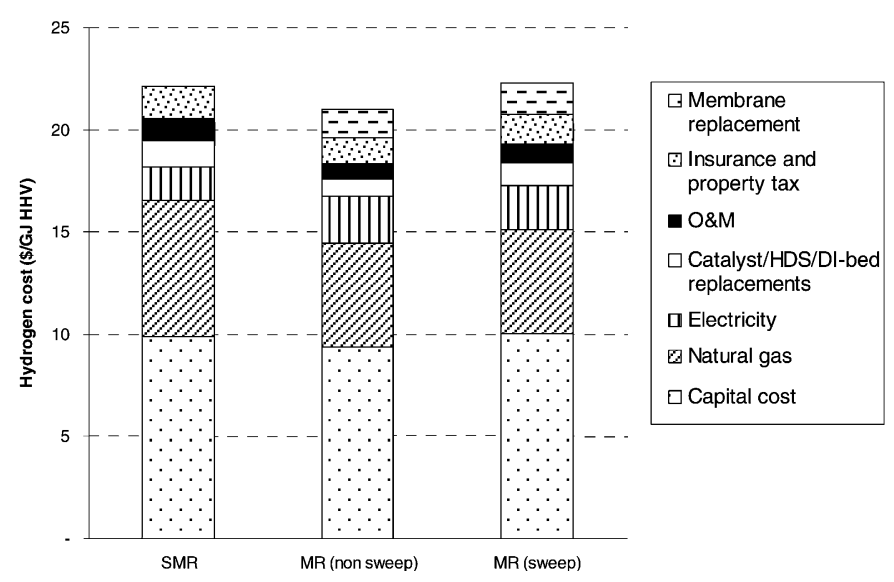

Fig. 8. Hydrogen cost comparison with SMR (0.2 MW).

comparison. A good comparison however can be made with a conventional steam reformer. For this, the economic evaluation performed by Myers et al. [24] is chosen since component cost data used here is largely taken from that report. The same capacity and economic parameters are assumed. ${ }^{20}$ The cost represents the wholesale hydrogen cost at a refuelling station, i.e. including hydrogen storage and dispensing cost as reported in [24].

Fig. 8 illustrates that, within the error margin, the final hydrogen cost for the MR is competitive with the SMR and potentially even cheaper, mainly due to the higher efficiency of the reformer and the use of less expensive steel. It should be emphasised that this is for a very small scale $(0.2 \mathrm{MW})$. For larger scales, hydrogen production cost for a MR will be higher than for a SMR as upscaling has a more beneficial effect on the SMR.

\subsubsection{Monte Carlo analysis}

To evaluate the effect of potential uncertainties in the main assumptions a Monte Carlo analysis has been performed. The parameters are varied with ranges given in Table 9 according to a triangular distribution. According to the analysis, the mean hydrogen costs for the non-sweep configuration without $\mathrm{CO}_{2}$ capture is around $14.5 \$ / G J$ and the median around $14.0 \$ / \mathrm{GJ}$ with a standard deviation of $3.1 \$ / \mathrm{GJ}$. A certainty level of $55 \%$ was calculated for the range between 12 and $16 \$ /$ GJ. Given the uncertainty in the assumptions, the most probable value is higher than the default result, which should be borne in mind when evaluating the MR against competitive alternatives.

Fig. 9 shows that the cost is most sensitive to membrane thickness. Reducing membrane thickness to $5 \mu \mathrm{m}$ lowers hydrogen cost to under $12 \$ / \mathrm{GJ}$, but it can easily approach $20 \$ / \mathrm{GJ}$ when a thickness larger than $30 \mu \mathrm{m}$ is used. With a membrane lifetime currently obtained by MRT (only 15 months), cost would reach 16 \$ GJ and the impact of a lower load factor illustrates the importance of matching reformer capacity and expected demand. Related to a refuelling station it is hence of utmost importance to continuously operate the reformer and have sufficient storage capacity.

The effect of the palladium price should also be emphasised due to the extreme volatility of its market price. In the last few decades, it has fluctuated from 1600 to 32,000 \$/ kg [89], even more than the range assumed here, which already results in a deviation of $2 \$ / G J$ to the default value. Natural gas and electricity prices are assumed for small-scale industrial users. Hence, long-term contracts with suppliers for more than just one refuelling station could greatly decrease production cost. However, it can be doubted whether natural gas prices drop again to levels below 4 \$ GJ considering recent increase in oil and hence gas prices (even for large industrial users).

\footnotetext{
${ }^{20}$ Load factor: $8585 \mathrm{~h}$, lifetime $10 \mathrm{yr}$, electricity price: $0.075 \$ / \mathrm{kWh}$, gas price: $0.19 \$ / \mathrm{m}^{3}$ and peak capacity: $115 \mathrm{~kg} \mathrm{H}_{2} / \mathrm{h}$. Storage, dispenser and miscellaneous cost for the refuelling station have also been taken equal. Hydrogen is compressed to 482 bar.
} 
Table 9

Ranges used for Monte Carlo analysis

\begin{tabular}{lll}
\hline & Default value & Range \\
\hline Membrane thickness & $20 \mu \mathrm{m}$ & $5-35 \mu \mathrm{m}$ \\
Natural gas price & $0.15 \$ / \mathrm{m}^{3}$ & $0.07-0.23 \$ / \mathrm{m}^{3}$ \\
Palladium price & $6,752 \$ / \mathrm{kg}$ & $2,888-10,615 \$ / \mathrm{kg}$ \\
Electricity price & $0.07 \$ / \mathrm{kWh}$ & $0.03-0.11 \$ / \mathrm{kWh}$ \\
Load factor & $80 \%(7008 \mathrm{~h})$ & $67-93 \%$ \\
Lifetime membranes & $3 \mathrm{yr}$ & $1.3-4.7 \mathrm{yr}$ \\
Membrane production cost & $1.5 \mathrm{raw}$ material cost & $0.9-2.1 \mathrm{raw}$ material cost \\
Discount rate & $13 \%$ & $8-18 \%$ \\
\hline
\end{tabular}

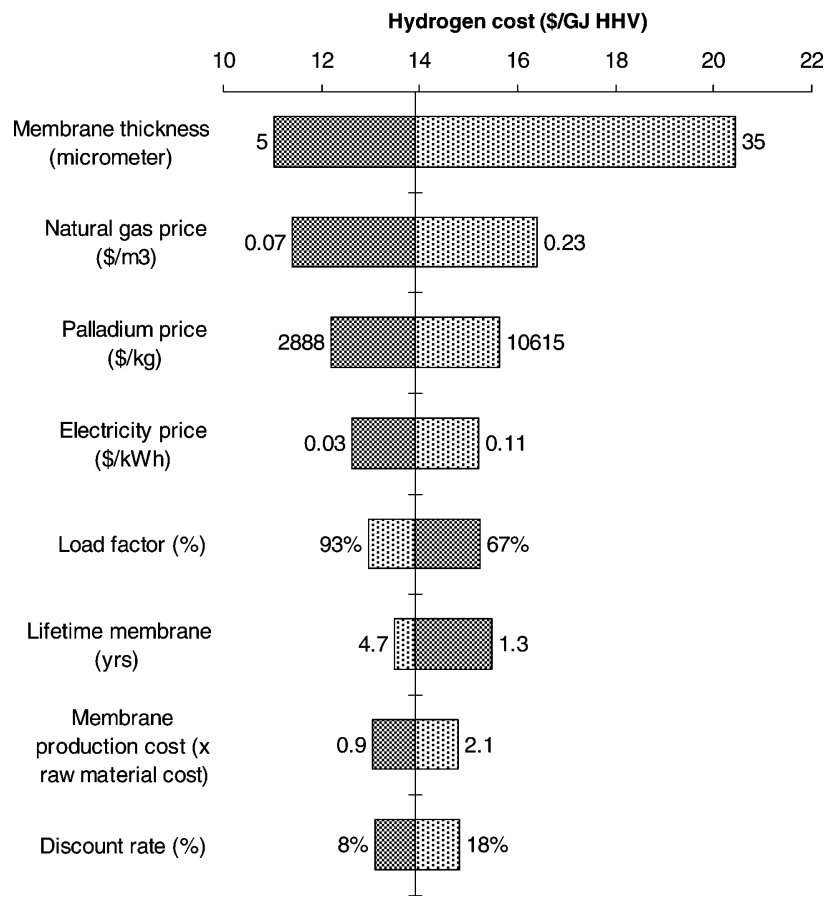

Fig. 9. Sensitivity analysis non-sweep MR (2MW) - parameter ranges are given in the figure.

\section{Fuel supply chain analyses}

\subsection{Methodology and assumptions}

In this section, the membrane reactor is evaluated in relation to other natural gas-fired technologies for a future hydrogen transportation infrastructure. The calculations in this section are mainly to provide an initial insight in small-scale $\mathrm{CO}_{2}$ capture and to examine the trade-off between the various fuel supply chains. The results should therefore be regarded as a first indication of the total fuel supply costs.

To enable a correct comparison between the different technologies, they need to be investigated on a wellto-wheel basis. That is, the total fuel supply chain from extracting the primary fuel to the utilisation of the hydrogen in a vehicle needs to be taken into account.

For the energy requirements, a spreadsheet model developed at Imperial College London is used [90]. The model can simulate any technically feasible hydrogen infrastructure with the infrastructure configuration and demand being defined by the user. The energy requirement per infrastructure component is an output and is 


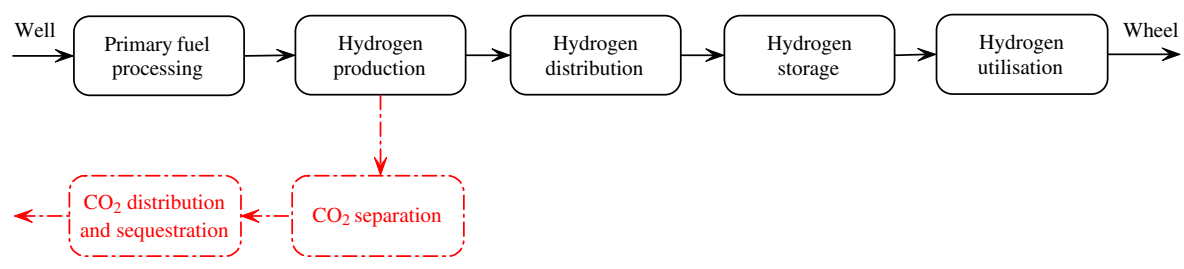

Fig. 10. Well-to-wheel chain including $\mathrm{CO}_{2}$ sequestration.

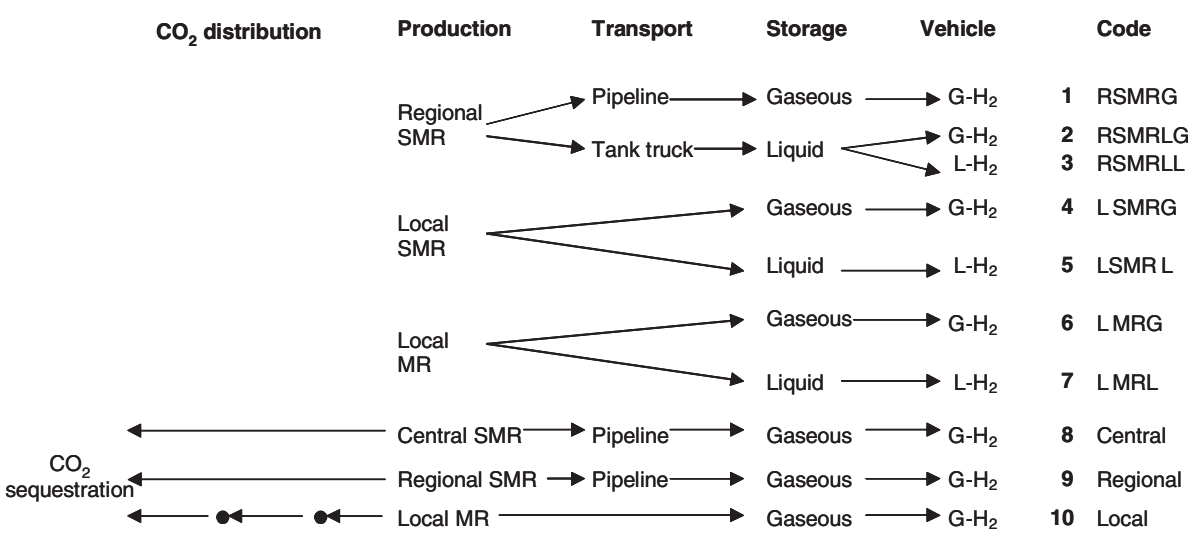

Fig. 11. Overview fuel supply chains.

subsequently used in another spreadsheet model to estimate the total costs required for installing and operating the infrastructure.

Fig. 10 gives a representation of the well-to-wheel chain for the hydrogen transportation sector and Fig. 11 shows all chains investigated. The primary fuel (in our case natural gas) is extracted, processed and distributed to a reformer where hydrogen is produced. Three reformer capacities are considered: a central unit of 400 MW, a regional unit of $40 \mathrm{MW}$ and a local unit at a refueling station of $2 \mathrm{MW}$. The hydrogen can be produced as a gas $\left(\mathrm{G}-\mathrm{H}_{2}\right)$ or as a liquid $\left(\mathrm{L}-\mathrm{H}_{2}\right)$. Hydrogen produced at centralised reformers (40 and $\left.400 \mathrm{MW}\right)$ needs to be distributed to the refuelling stations, either in gaseous form through pipelines or as a liquid with tank trucks. Subsequently, the hydrogen is stored and dispensed to a vehicle, running on gaseous or liquid hydrogen.

The production of hydrogen can also be done with $\mathrm{CO}_{2}$ separation, followed by transport and sequestration of the $\mathrm{CO}_{2}$. For the small-scale $\mathrm{SMR}$, cost of $\mathrm{CO}_{2}$ sequestration is prohibitive [3] and is therefore omitted. The same applies to the non-ideal MR configuration (with cryogenic separation) as cost is more than three times that of the ideal configuration. Since sequestration cost is equal for both states of hydrogen, only gaseous is chosen. The option is therefore researched for the MR ( $2 \mathrm{MW}$ ideal) and for the regional and central SMR (40 and $400 \mathrm{MW}$ ).

The distribution infrastructure is shown in Table 10 with all branches originating at the reformer. The infrastructure is based on hydrogen supply to 200 refuelling stations of $2 \mathrm{MW}$ hydrogen demand each and distances are based on the Netherlands. The calculations for the required pipeline diameter are done using steady-state flow equations, given a certain input pressure and pressure drop. The calculated pipeline diameters correspond well with the values given in Ogden [92] and MIT [93].

Regarding the carbon dioxide infrastructure, it is assumed that a large-scale $\mathrm{CO}_{2}$ distribution grid is already in place, as illustrated in Fig. 12. The volumetric flow assumed through the third branch is therefore much bigger than when only hydrogen production plants are considered. We assumed a wellhead pressure of 80 bar. Hence, compression at the plant is done up to 90 or 100 bar depending on the distance that needs to be covered. Table 11 shows the costs and energy requirements of the various components for the fuel supply 
Table 10

Pipeline infrastructure assumptions

\begin{tabular}{|c|c|c|c|c|c|}
\hline \multirow[t]{2}{*}{ Scale } & \multicolumn{2}{|c|}{$\mathrm{H}_{2}$ infrastructure } & \multicolumn{3}{|c|}{$\mathrm{CO}_{2}$ infrastructure } \\
\hline & Regional & Central & Local & Regional & Central \\
\hline \multicolumn{6}{|l|}{ 1st branch } \\
\hline Input pressure (bar) & 60 & $70^{\mathrm{a}}$ & 100 & 100 & 90 \\
\hline Flow & - & $400 \mathrm{MW}$ & $2.2 \mathrm{ktCO}_{2} / \mathrm{yr}$ & - & - \\
\hline Distance $(\mathrm{km})$ & - & 50 & 10 & - & - \\
\hline Number of pipelines & - & 1 & 200 & - & - \\
\hline Pressure drop (bar) & - & 10 & 1 & - & - \\
\hline Diameter $(\mathrm{m})$ & - & 0.25 & 0.03 & - & - \\
\hline \multicolumn{6}{|l|}{ 2nd branch } \\
\hline Flow & $40 \mathrm{MW}$ & $40 \mathrm{MW}$ & $44 \mathrm{kt} \mathrm{CO}_{2} / \mathrm{yr}$ & $44 \mathrm{kt} \mathrm{CO}_{2} / \mathrm{yr}$ & - \\
\hline Distance $(\mathrm{km})$ & 30 & 30 & 30 & 30 & - \\
\hline Number of pipelines & 10 & 10 & 10 & 10 & - \\
\hline Pressure drop (bar) & 10 & 10 & 5 & 5 & - \\
\hline Diameter $(\mathrm{m})$ & 0.10 & 0.10 & 0.08 & 0.08 & - \\
\hline $3 r d$ branch & \multicolumn{2}{|c|}{ To refuelling station } & \multicolumn{3}{|c|}{ To sequestration site } \\
\hline Flow & $2 \mathrm{MW}$ & $2 \mathrm{MW}$ & $5 \mathrm{MtCO}_{2} / \mathrm{yr}$ & $5 \mathrm{MtCO}_{2} / \mathrm{yr}$ & $5 \mathrm{MtCO}_{2} / \mathrm{yr}$ \\
\hline Distance $(\mathrm{km})$ & 10 & 10 & 100 & 100 & 100 \\
\hline Number of pipelines & 200 & 200 & 1 & 1 & 1 \\
\hline Pressure drop (bar) & 1 & 1 & 10 & 10 & 10 \\
\hline Diameter $(\mathrm{m})$ & 0.05 & 0.05 & 0.50 & 0.50 & 0.50 \\
\hline
\end{tabular}

${ }^{\mathrm{a}}$ After [113]; for the regional reformer, input pressure has been assumed 60 bar to ensure the same output pressure at the refuelling station as for the central reformer.

chain analysis. The lifetime of all components is set at 15 years, except for transport components (pipelines $22 \mathrm{yr}$ and trucks $10 \mathrm{yr}$ [95]). In agreement with other infrastructure estimates, costs do not include land cost and labour at the refuelling station and consistent with the market, utility prices for centralised production are lower than for decentralised. For large-scale production $3.3 \$ / \mathrm{GJ}$ natural gas and $0.05 \$ / \mathrm{kWh}$ electricity are assumed.

\subsection{Results fuel supply chains}

The wholesale hydrogen cost for all chains, including those with $\mathrm{CO}_{2}$ sequestration, is given in Fig. 13. Liquid hydrogen is more expensive compared to gaseous hydrogen owing to the high energy use and capital costs of liquefaction. Although centralised steam reforming is much cheaper than on-site (8 \$/GJ versus $13 \$ /$ $\mathrm{GJ})$, the additional investment in distribution infrastructure increases total hydrogen cost for regional production (RSMRG) to a level close to that of local (LSMRG). While this indicates that on-site SMR could approach the cost of centralised, one should bear in mind that this is strongly dependent on the assumption of mass production. It is currently based on 250 units, but at higher production volumes the cost difference will be more in favour of small-scale reforming (see also Section 5.3). Recalling the number of refuelling stations in the Netherlands (4200), the latter situation seems more likely and implies that on-site steam reforming could potentially be as cost-effective as centralised to supply hydrogen to refuelling stations.

Owing to the high cost of reforming and compression, the membrane reactor (LMRG) gives a higher hydrogen cost than the SMR: 17 \$/GJ versus 15 \$/GJ (regional) and 16 \$/GJ (local). It was already indicated that upscaling has a more beneficial effect on the SMR than on the MR. Hence, the higher capacity assumed here makes the SMR slightly less expensive than the MR. By reducing membrane thickness to less than $10 \mu \mathrm{m}$, cost will approach that of regional steam reforming $(15 \$ / G J)$.

Including $\mathrm{CO}_{2}$ sequestration in the hydrogen cost, the final cost for the MR (19 \$/GJ) nears that for the regional SMR (18 \$/GJ). Fig. 14 shows the disaggregated cost of $\mathrm{CO}_{2}$ separation, transport and sequestration. 


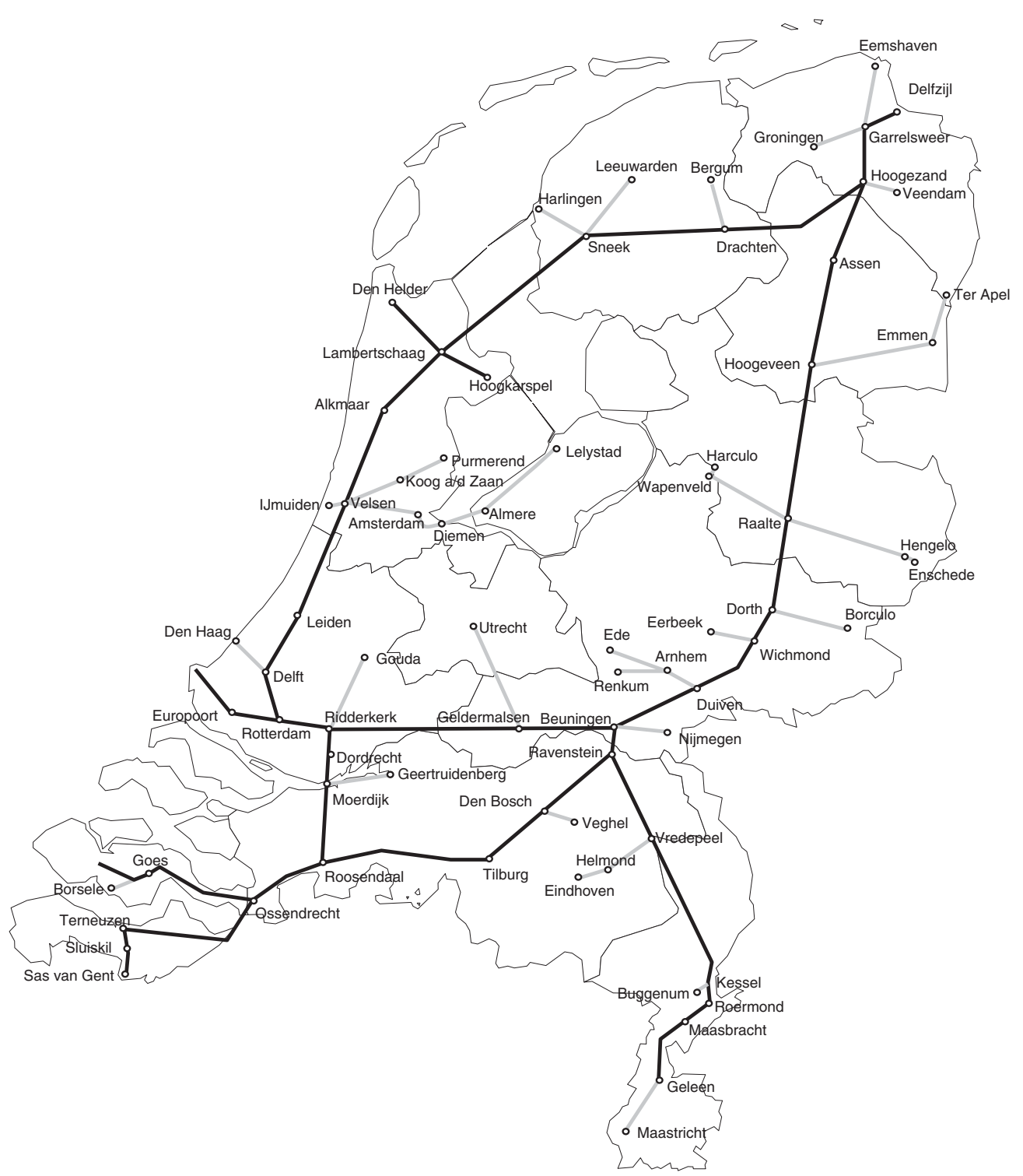

Fig. 12. Potential configuration of a large scale $\mathrm{CO}_{2}$ distribution network [91].

It demonstrates the low cost of $\mathrm{CO}_{2}$ separation with the $\mathrm{MR}$ in comparison to conventional technology. Whereas the separation cost for the local scenario is less, $\mathrm{CO}_{2}$ distribution needs additional investment since a network from the stations to the grid is necessary. Especially the smallest capacity pipelines (1st branch) contribute considerably $(45 \%)$ to the total cost and is the main cause that sequestration cost $\left(46 \$ / \mathrm{CO}_{2}\right)$ exceeds that of the central scenario $\left(42 \$ / \mathrm{t} \mathrm{CO}_{2}\right)$.

If we consider a best-case scenario in which thin membranes (several $\mu \mathrm{m}$ ) and industrial utility prices are assumed, ${ }^{21}$ first estimates of hydrogen cost are ca. $14 \$ / \mathrm{GJ}$ including $\mathrm{CO}_{2}$ sequestration and can decrease even further with higher production capacity. This is less than large-scale hydrogen production with $\mathrm{CO}_{2}$ sequestration $(15 \$ / G J)$ and would make small-scale $\mathrm{CO}_{2}$ separation with membrane reactors an attractive infrastructure option.

\footnotetext{
${ }^{21}$ Equal to large-scale production.
} 
Table 11

Parameters for the fuel supply chain equipment

\begin{tabular}{|c|c|c|c|c|c|}
\hline Component & $\begin{array}{l}\text { Efficiency or } \\
\text { energy } \\
\text { consumption }\end{array}$ & $\begin{array}{l}\text { Base cost } \\
(000 \$)\end{array}$ & $\begin{array}{l}\text { Base } \\
\text { scale }\end{array}$ & $\begin{array}{l}\text { Scale factor or } \\
\text { engineering equation }\end{array}$ & O\&M $(\%)^{\mathrm{a}}$ \\
\hline \multicolumn{6}{|l|}{ Reforming } \\
\hline Regional/central SMR plant & $85 \%$ b & 13,844 & $24.4 \mathrm{tpd}$ & $455,820 x+2,721,841^{\mathrm{c}}$ & $4^{\mathrm{d}}$ \\
\hline Local SMR plant & $80 \%{ }^{\mathrm{e}}$ & $233^{\mathrm{f}}$ & $0.12 \mathrm{tpd}$ & $0.7^{\mathrm{g}}$ & 4 \\
\hline Local MR plant & $82 \%{ }^{\mathrm{h}}$ & $829^{\mathrm{i}}$ & $0.97 \mathrm{tpd}$ & $0.85^{\mathrm{j}}$ & $4^{\mathrm{k}}$ \\
\hline \multicolumn{6}{|l|}{ Compression } \\
\hline Hydrogen compressor & $78 \% 1$ & $30^{\mathrm{m}}$ & $10 \mathrm{~kW}$ & 0.6 & 4 \\
\hline \multicolumn{6}{|l|}{ Liquefaction } \\
\hline Central hydrogen liquefier & $0.848 \mathrm{kWh} / \mathrm{Nm}^{3} \mathrm{H}_{2}{ }^{\mathrm{n}}$ & 33,432 & $24.4 \mathrm{tpd}$ & $-1,315 x^{2}+1,146,035 x+5,500,940^{\circ}$ & 3 \\
\hline On-site hydrogen liquefier & $0.848 \mathrm{kWh} / \mathrm{Nm}^{3} \mathrm{H}_{2}$ & $4455^{\mathrm{p}}$ & 4.5 tpd & $0.68^{\mathrm{q}}$ & 3 \\
\hline \multicolumn{6}{|l|}{ Storage } \\
\hline Gaseous storage $^{r}$ & - & $66^{\mathrm{s}}$ & $79 \mathrm{~kg}$ & $0.65^{t}$ & 2 \\
\hline Liquid storage $^{\mathrm{u}}$ & - & 103 & $3.1 \mathrm{t}$ & $17,221 x+49,932^{\mathrm{v}}$ & 2 \\
\hline \multicolumn{6}{|l|}{ Dispensing } \\
\hline On-site pump/vaporiser ${ }^{w}$ & $0.063 \mathrm{kWh} / \mathrm{Nm}^{3} \mathrm{H}_{2}{ }^{\mathrm{x}}$ & 171 & $1.2 \mathrm{tpd}$ & $-8670 x^{2}+128,085 x+29,566^{\mathrm{y}}$ & 3 \\
\hline Gaseous dispenser & $\mathrm{z}^{\mathrm{z}}$ & 137 & $1.2 \mathrm{tpd}$ & $99,652 x+17,785^{\text {aa }}$ & 4 \\
\hline Liquid dispenser & - & 127 & $1.2 \mathrm{tpd}$ & $93,880 x+14,339^{b b}$ & 4 \\
\hline \multicolumn{6}{|l|}{ Transport } \\
\hline Pipelines & - & - & - & $0.827 \cdot 1.5 \cdot$ diameter $(\mathrm{m})$ length $(\mathrm{km})^{\mathrm{cc}}$ & 2.1 \\
\hline Truck transport ${ }^{\mathrm{dd}}$ & 0.39 lts diesel $/ \mathrm{km}^{\mathrm{ee}}$ & 545 & 1 truck & - & 2 \\
\hline \multicolumn{6}{|l|}{$\mathrm{CO}_{2}$ capture and storage $^{\mathrm{ff}}$} \\
\hline $\begin{array}{l}\mathrm{CO}_{2} \text { separation } \\
\text { (chemical absorption) }^{\mathrm{gg}}\end{array}$ & $90 \% \mathrm{CO}_{2}$ capture Efficiency ${ }^{\mathrm{hh}}$ & $27,270^{\mathrm{ii}}$ & $42 \mathrm{t} \mathrm{CO}_{2} / \mathrm{h}$ & $0.6^{\mathrm{jj}}$ & \\
\hline $\mathrm{CO}_{2}$ compressor & $78 \%{ }^{\mathrm{kk}}$ & $3000^{11}$ & $6 \mathrm{MW}$ & $0.67^{\mathrm{mm}}$ & 4 \\
\hline $\mathrm{CO}_{2}$ pipelines & - & - & - & 0.827 diameter $(\mathrm{m})$ length $(\mathrm{km})^{\mathrm{nn}}$ & $2.1^{\mathrm{oo}}$ \\
\hline $\mathrm{CO}_{2}$ sequestration ${ }^{\mathrm{pp}}$ & - & 3.47 & $\$ / \mathrm{t} \mathrm{CO}_{2}$ & - & - \\
\hline Refuelling station & - & $1500^{\mathrm{qq}}$ & - & - & - \\
\hline
\end{tabular}

\footnotetext{
${ }^{\mathrm{a}}$ Unless stated otherwise, all O\&M percentages are taken from [102]. Values are given in percentages of total capital investment.

${ }^{\mathrm{b}}$ At present, the efficiency of large-scale reformers can vary from $76 \%$ to $85 \%$ HHV $[23,114,115]$ depending on whether steam export is taken into account. The highest value is taken representing efficiency gains expected for the medium term. The output pressure of $\mathrm{H}_{2}$ after the reformer and prior to the compressor is assumed 25 bar [23,116,117].

${ }^{\mathrm{c}}$ The engineering equation is a linear fit to costs given in [24,118-120]. This equation is practically identical to a different engineering equation for large-scale SMR quoted in [121].

${ }^{\mathrm{d}}$ This includes costs for labor, chemicals etc. [102].

${ }^{\mathrm{e}}$ The efficiency of small-scale reformers ranges currently from $70 \%$ to $80 \%$ HHV [24,80,114]. Highest value is also taken here representing efficiency gains expected for the medium term. The output pressure of $\mathrm{H}_{2}$ after the reformer and prior to the compressor is assumed 9 bar, after [24,110]. It is more beneficial to operate a small-scale SMR at lower pressure than a large-scale SMR.

${ }^{\mathrm{f}}$ Taken from [24]. This estimate has also been based on a production volume of 250 units and can thus be compared to the MR. The cost is for the reformer increased with $42.5 \%$ to account for installation, contingency and tax and insurance.

${ }^{\mathrm{g}}[86]$.

${ }^{\mathrm{h}}$ Taken from the Aspen analysis, efficiency excluding compression (see Section 5.2). Hydrogen outlet pressure is 1 bar prior to compression.

${ }^{\mathrm{i}}$ Total capex determined by the economic analysis in Section 5.3, excluding hydrogen compressor.

${ }^{\mathrm{j}}$ Calculated in Section 5.3.1.

${ }^{\mathrm{k}}$ Normal O\&M is $4 \%$. An extra $5 \%$ needs to be included for membrane replacement.

${ }^{\mathrm{l}}[60,99]$.

${ }^{\mathrm{m}}$ Data for multi-stage compressor. Cost given together with a scaling factor of 0.6 [105] gives a good fit to multi-stage compressor costs mentioned in other studies [1,24,122]. Cost reduction of $40 \%$ is assumed since production volume is 250 units (confidential).

${ }^{\mathrm{n}}$ Liquefying plants are available in capacities of $1-60 \mathrm{tpd}$, supplied by, e.g Linde Gas and Air Liquide [123]. The energy required for liquefaction has a range of $10.1-15 \mathrm{kWh} / \mathrm{kg}$ hydrogen produced [1,124]. The lowest estimate is assumed to represent efficiency in the medium term $\left(10.1 \mathrm{kWh} / \mathrm{kg}=0.8484 \mathrm{kWh} / \mathrm{Nm}^{3}\right)$.
} 
${ }^{\circ}$ Polynomial fit to cost data taken from [1,102,123,119].

${ }^{\mathrm{p}}$ Cost estimate for the smallest capacity liquefier has been chosen [123]. For consistency reasons the capital cost of the small liquefaction unit has also been calculated for a production volume of 250 units with a learning rate of $86 \%$. Methodology is described in [119] and the learning rate is equal to other renewable energy technologies [24].

${ }^{\mathrm{q}}$ Average scaling factor for general equipment assumed [105].

${ }^{\mathrm{r}}$ Gaseous storage at 482 bar at the refuelling station. Storage capacity required is $70 \%$ of daily demand assuming a daily demand profile as given in [119] and that $58 \%$ of the hydrogen cannot be recovered with cascade dispensing [52]. Storage at the refuelling station after pipeline transport may be less as it is immediately taken from the grid. At the central plant storage capacity is 0.5 times the daily production [125].

s[24]. The cost may be reduced considerably when composite materials are utilised.

${ }^{\mathrm{t}}$ Scaling factor for horizontal pressurised storage tanks [105].

${ }^{\mathrm{u}}$ At the centralised plant: 0.5 times the daily production [113]; Liquid $\mathrm{H}_{2}$ boil-off is assumed $0.03 \%$ /day [123]. At the refuelling station, storage is one time the daily demand to enable one daily truck delivery.

${ }^{\mathrm{v}}$ Engineering equation is a linear fit to cost data reported in [95,102,118,126].

${ }^{\mathrm{w}}$ Nominal capacity of all dispensers is $0.25 \mathrm{tpd}$.

${ }^{\mathrm{x}}[127]$.

${ }^{\mathrm{y}}$ Engineering equation is a polynomial fit to cost data reported in $[1,118,126]$.

${ }^{\mathrm{z}}$ Gaseous cascade dispensing and liquid dispensing requires very little energy and has therefore been neglected.

${ }^{\text {aa }}$ Equation is a linear fit to data from $[24,118,119,126]$; there is remarkable agreement between the various literature estimates.

${ }^{\mathrm{bb}}$ Linear fit to data from $[118,119,126]$.

${ }^{\mathrm{cc}}$ Pipeline cost is taken from [93]. This estimate is based on empirical data of more than 10 years for the capital cost of natural gas pipelines. It is then multiplied by a factor of 1.5 to account for hydrogen instead of natural gas, following [92]. Hydrogen pipelines need higher quality material to prevent hydrogen embrittlement.

${ }_{\mathrm{dd}}$ Truck transport is calculated by round-trip, i.e. two-way to deliver one load. Total truck and O\&M cost taken from [95]. Diesel price is $0.8 \$ / 1$ (EU average 2001-2003, [96]), drivers wage is $31.5 \$ / \mathrm{h}$ and average speed is $40 \mathrm{~km} / \mathrm{h}$ [95].

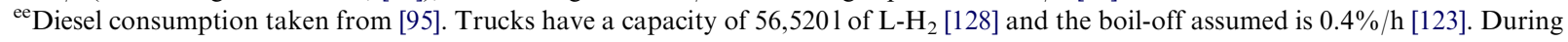
transfer of the hydrogen from tank to truck and vice versa some hydrogen may be lost as well [95], but this has been neglected.

${ }^{\mathrm{ff}} \mathrm{All}$ cost for $\mathrm{CO}_{2}$ sequestration are given in $\mathrm{t} / \mathrm{CO}_{2}$ captured.

${ }^{\mathrm{gg}}$ The separation technology assumed is a chemical absorption unit using mono-ethylamine (MEA) due to the low partial pressure of $\mathrm{CO}_{2}$. Amines are the most suitable for $\mathrm{CO}_{2}$ removal at SMR $[129,130]$.

${ }^{\mathrm{hh}}$ Capture efficiency can range from $90 \%$ to $98 \%$ [131]. Higher efficiency comes at a considerable higher cost; the lowest value has therefore been used.

${ }^{\text {ii } V a l u e ~ t a k e n ~ f r o m ~[132] ~ a s s u m i n g ~ o f f-g a s ~ w i t h ~ a ~} \mathrm{CO}_{2}$ concentration of $13 \%$ [61]. The operational cost has also been taken from this source: $19.9 \$ / \mathrm{t} \mathrm{CO}_{2}$. The formula given by Chapel coincides with the value given by Hendriks [131].

${ }_{\mathrm{jj}}[132]$ mentions a scale factor of $0.5-0.6$; highest value is assumed here.

${ }^{\mathrm{kk}}$ The compression energy required is calculated with the conventional engineering equation as given in [61].

${ }^{11}[107]$.

$\mathrm{mm}_{[133] .}$

nn $[93]$.

${ }^{\circ}$ Based on [134]; O\&M cost consists of pipeline pigging, anti-corrosive measures, cathodic protection, monitoring the control equipment and odorisation.

${ }_{\mathrm{pp}}^{\mathrm{p}}$ The cost for sequestration has been assumed equal for all scenarios. This cost strongly depends on the geological site; here the cost at an on-shore aquifer of $2 \mathrm{~km}$ depth has been taken from Hendriks et al. [135].

${ }^{\mathrm{qq}}$ Capital cost of a 2.4 tpd refuelling station is $\$ 1.5$ million [113]. This is divided into $80 \%$ compression and storage and $20 \%$ construction and other miscellaneous necessities. To account for the latter, $\$ 300,000(20 \%$ of $\$ 1.5$ million) is added to the cost of the centralised production chains. For the reformer in the decentralised chains this has already been included. To account for installation and unforeseen costs $20 \%$ has been added to the capital cost of storage, compressor and dispenser [24].

To assess the advantage of the MR for emission reduction, an indication of the $\mathrm{CO}_{2}$ mitigation costs are given. We assume a 'business-as-usual' scenario in which gasoline continues to be used as a fuel in (advanced) internal combustion engines vehicles. The $\mathrm{CO}_{2}$ mitigation costs are then calculated by dividing the cost difference per $\mathrm{km}$ with the difference in $\mathrm{CO}_{2}$ emissions per $\mathrm{km}$ between a hydrogen FCV and a gasoline ICEV. Without taxes or profit, gasoline costs $9 \$ / \mathrm{GJ}$ at a refuelling station in the $\mathrm{EU}^{22}$ [96] and hydrogen $18 \$ / \mathrm{GJ}$ for the MR including $\mathrm{CO}_{2}$ sequestration. ${ }^{23}$ For advanced ICEVs the fuel economy is $1.1-1.6 \mathrm{MJ} / \mathrm{km}$ and for

\footnotetext{
${ }^{22}$ Based on a production price of $0.30 \$ / 1$ for gasoline and $0.305 \$ / 1$ for diesel in the EU $2001-2003$. Energy content is $34.5 \mathrm{MJ} / 1$ gasoline and $38.5 \mathrm{MJ} / 1$ diesel.

${ }^{23}$ For the ideal configuration $33.7 \mathrm{~kg} \mathrm{CO}_{2} / \mathrm{GJ}_{\mathrm{H} 2}$ is emitted (heat production and electricity generation). An emission factor of $560 \mathrm{~g} \mathrm{CO} /$ $\mathrm{kWh}_{\mathrm{e}}$ is assumed for electricity generation [97].
} 


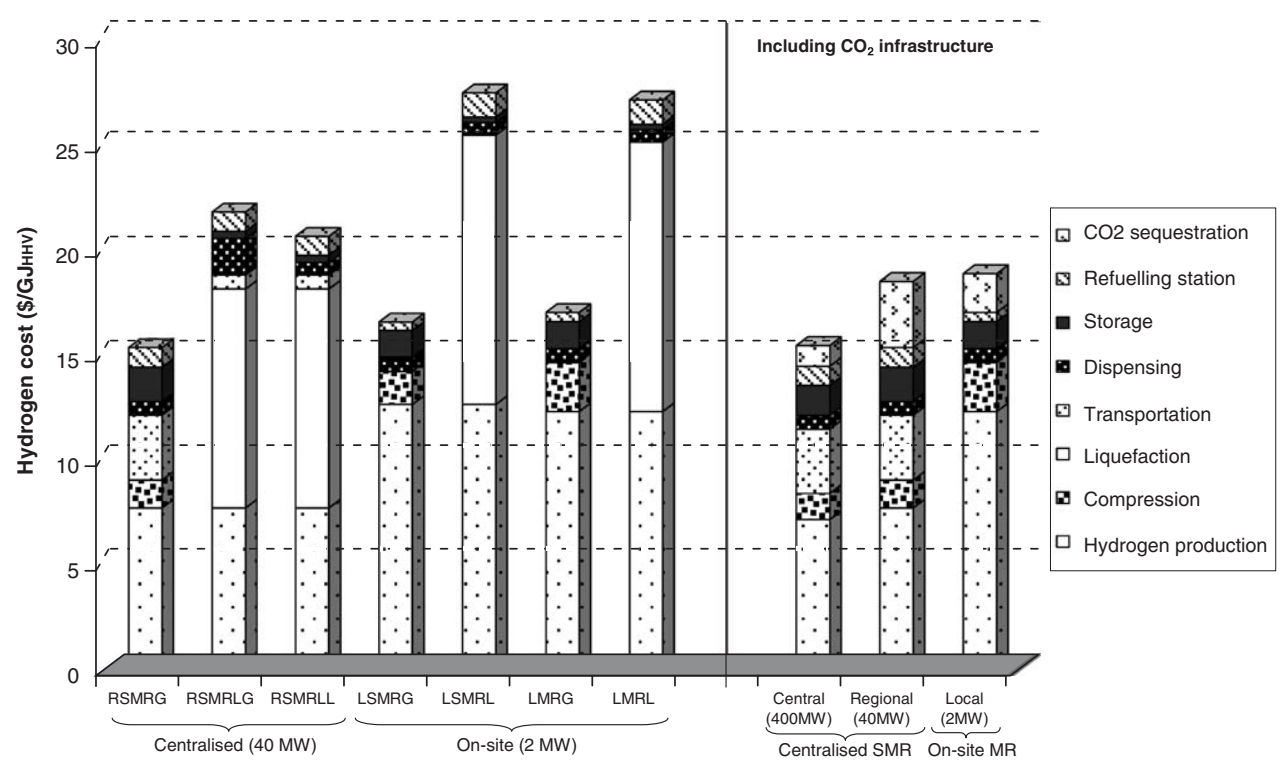

Fig. 13. Levelised hydrogen cost $\left(\mathrm{CO}_{2}\right.$ sequestration includes $\mathrm{CO}_{2}$ capture and transport).

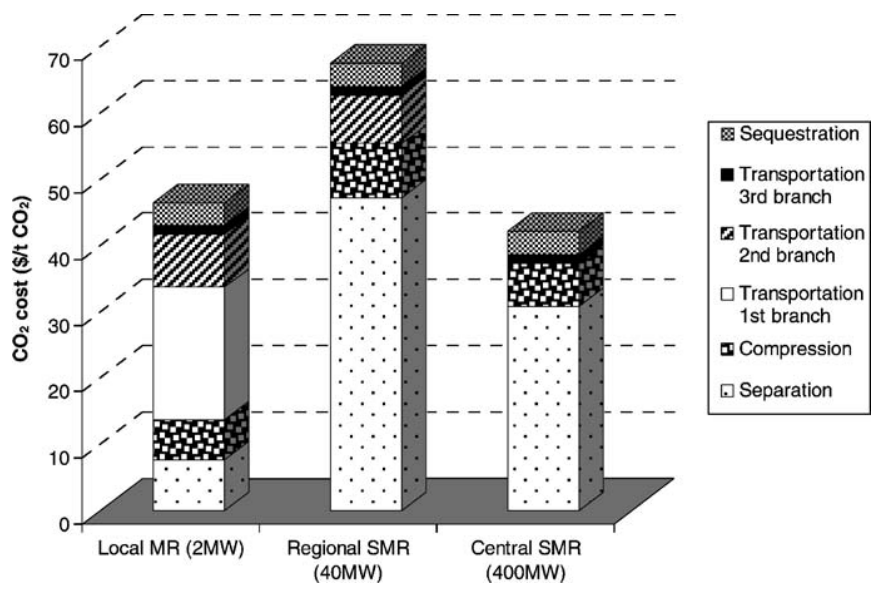

Fig. 14. $\mathrm{CO}_{2}$ sequestration cost.

FCVs fuelled with hydrogen $0.6-1.8 \mathrm{MJ} / \mathrm{km} .{ }^{24}$ Taking the most efficient values this results in a fuel cost of 1 $\$_{\mathrm{ct}} / \mathrm{km}$ for gasoline and $1.1 \$_{\mathrm{ct}} / \mathrm{km}$ for hydrogen. Including investment for the car (see for more detail: [97]), costs are $16.4 \$_{\mathrm{ct}} / \mathrm{km}$ for gasoline and $18.1 \$_{\mathrm{ct}} / \mathrm{km}$ for hydrogen. With a reference emission for future ICEVs of $100 \mathrm{~g} \mathrm{CO}_{2} / \mathrm{km}$ [97] and emissions for hydrogen production with the $\mathrm{MR}$ of $20 \mathrm{~g} \mathrm{CO}_{2} / \mathrm{km}$, final $\mathrm{CO}_{2}$ mitigation cost is approximately $200 \$ / \mathrm{tCO}_{2}$ avoided. Considering the current $\mathrm{CO}_{2}$ emission market price of about $20 \$ / \mathrm{t}$ $\mathrm{CO}_{2}$, hydrogen production with the $\mathrm{MR}$ and $\mathrm{CO}_{2}$ sequestration is an expensive option for $\mathrm{CO}_{2}$ emission reduction.

\section{Conclusions}

The small-scale membrane reactor has been evaluated in relation to its future economic and thermodynamic potential including its prospect of inexpensive $\mathrm{CO}_{2}$ separation. The studied configurations for the reformer

\footnotetext{
${ }^{24} 80 \mathrm{mpge}$ is equivalent to $1 \mathrm{MJ} / \mathrm{km}$ [24]. $1.8 \mathrm{MJ} / \mathrm{km}$ is the fuel economy of a current fuel cell vehicle [82].
} 
have been specifically designed as on-site hydrogen production facilities, envisaged at refuelling stations in a future transportation infrastructure.

The main promises of the membrane reactor such as higher methane conversion at lower temperature and higher total efficiency compared to conventional steam reforming are confirmed. The highest efficiency attained with the MR is $84 \% \mathrm{HHV}$ without hydrogen compression and $78 \%$ with compression ( 482 bar) for the non-sweep configuration. The sweep configuration is $0.5 \%$ pt less efficient. Optimal heat integration, higher natural gas feed pressure and improved membrane performance may give further efficiency improvement.

Hydrogen production cost with a MR is competitive with conventional steam reforming for a $0.2 \mathrm{MW}$ plant, but gets more expensive at larger capacities. This is mainly caused by the smaller benefit of upscaling for the MR due to its modular nature. For a $2 \mathrm{MW}$ MR hydrogen cost is $14 \$$ /GJ with the sweep configuration being a few percent more expensive than non-sweep. The inherent uncertainty in the input assumptions showed that there is a large range of values possible with the most likely value around $14.5 \$ / G J$. Reducing membrane thickness is one of the best opportunities of making the technology competitive, but since this may also change the reaction dynamics we can only give a rough estimate. With a thickness of several micrometers, already realised in laboratory settings, production cost is lowered to less than $12 \$ / G J$. This would also reduce the risk related to the price volatility of palladium. Technological learning can contribute to further cost reductions as market volumes are expected to reach considerable quantities if hydrogen really takes off as a transportation fuel.

Several uncertainties are crucial with respect to the competitiveness of the MR. Assumptions on membrane permeability and lifetime remain to be proven in actual demonstration projects. Especially the effect of thermal cycling on the lifetime is important if one considers its application as an on-site reformer. Production technology of the membrane tubes is another fundamental issue that needs to be solved. At present, assembly of the membrane tubes is done by hand and constitutes an important part of the capital and annual cost. An inexpensive production method enabling machine assembly and thus the prospect of mass production and low gas prices are indispensable to lower costs. If these criteria are met, the MR will become a very competitive alternative to the SMR.

Of the ten different fuel supply chains analysed, centralised steam reforming is most economically viable, but on-site steam reforming with gaseous hydrogen as a product might be a competitive alternative. The final hydrogen cost is $15 \$ /$ GJ for a $40 \mathrm{MW}$ SMR compared to $16 \$ / \mathrm{GJ}$ for a $2 \mathrm{MW}$ SMR and $17 \$ / \mathrm{GJ}$ for a $2 \mathrm{MW}$ MR (all gaseous $\mathrm{H}_{2}$ ).

The modelling results also revealed that the MR has the potential of relatively inexpensive carbon dioxide capture. That is, as long as a minimum concentration of contaminants in the (mostly $\left.\mathrm{CO}_{2}\right)$ gas stream does not pose any problems to the pipeline distribution network (ideal). If the exit gas is not pure enough for pipeline transport a cryogenic separation unit is added to purify the $\mathrm{CO}_{2}$ stream. Including $\mathrm{CO}_{2}$ separation and compression, total system efficiency is lowered by a little over $1 \% \mathrm{pt}$, which is a low penalty in comparison to other systems with $\mathrm{CO}_{2}$ capture being studied/developed. Cost for a small-scale MR with cryogenic separation is expensive (almost $50 \$ / \mathrm{tCO}_{2}$ ), but the economic feasibility of the ideal situation is promising: ca. $14 \$ / \mathrm{tCO}_{2}$ separated. For small-scale $\mathrm{CO}_{2}$ capture, however, a distribution infrastructure is required to transport the $\mathrm{CO}_{2}$ to sequestration sites, resulting in a total sequestration cost of $46 \$ / \mathrm{t} \mathrm{CO}_{2}$ for the MR compared to $65 \$ / \mathrm{t} \mathrm{CO}_{2}$ for a $40 \mathrm{MW}$ centralised plant. For the latter a less extensive distribution infrastructure is necessary, but separation is more expensive. At larger plants this advantage disappears as both hydrogen production cost and $\mathrm{CO}_{2}$ sequestration cost are considerably reduced: hydrogen cost (including $\mathrm{CO}_{2}$ sequestration) is around $15 \$ / G J$ for a $400 \mathrm{MW}$ SMR versus $18 \$ /$ GJ for a $40 \mathrm{MW}$ SMR and $19 \$ /$ GJ for a $2 \mathrm{MW}$ MR. Regarding the trade-off between a $\mathrm{H}_{2}$ infrastructure and a $\mathrm{CO}_{2}$ infrastructure, it therefore strongly depends on the scale of centralised production whether $\mathrm{CO}_{2}$ sequestration with on-site membrane reactors should be considered.

In the "best-case" scenario for MR, which incorporates thin membranes, industrial utility prices and high production volumes, total cost for the MR can be reduced to less than $14 \$ / G J$ (including $\mathrm{CO}_{2}$ sequestration), thus making this scenario more attractive than large-scale production. However, total cost of $\mathrm{CO}_{2}$ sequestration would be $200 \$ / \mathrm{t} \mathrm{CO}$ avoided.

Finally, it should be noted that the modelling approach for the reactor is simplified and does not take into account reaction kinetics. Comparison of the results with other studies do indicate that the approach is sufficiently accurate for our techno-economic calculations, but as it does not represent the technology in all of 
its complexities, the results should be interpreted accordingly and as such only give an indication of the potential of the technology. Especially for thin membranes the accuracy of the calculations is reduced since thermodynamic and kinetic conditions may be slightly altered. It is therefore recommended that a more detailed model is developed to determine the possible impact of our assumptions.

This study has identified the following areas in need of further research:

- The performance of the membrane itself is a crucial factor. More RD\&D is needed to enable the production of a membrane that combines a thin layer, high flux and suitable stability in all operating conditions. It should also facilitate a cheap manufacturing method with the potential of mass production. Membrane materials other than palladium-based such as zeolites and amorphous silica could provide a cheaper and more stable alternative and should be investigated.

- The stability, reliability and lifetime of the reactor under normal operating conditions and with numerous start-up and shut-down cycles need to be improved. Especially the lifetime of the membrane tubes should be given extra attention.

- A more detailed modelling method is required to further optimise operating conditions.

- Experimental data should be gathered to verify the technical feasibility of $\mathrm{CO}_{2}$ separation with the MR.

- The relation between hydrogen storage, production and demand patterns should be evaluated.

- More in-depth analysis of trade off between size of production facility and infrastructure requirements.

\section{Acknowledgements}

We would like to acknowledge the help of Jan Wilco Dijkstra and Daniel Jansen (ECN) for giving more insight into the problem and for giving us a starting point by providing a preliminary model of a membrane system. We are also very grateful to David Joffe, Ausilio Bauen and David Hart of the Department of Environmental Technology at Imperial College for making part of this research possible. A special thanks goes to all the people that have given us information and insightful comments: Wayne Youngs (Toromont Process Systems), Jan Lambrichts (Cargill Dow), Arian Nijmeijer (Shell Global Solutions), Rodney Allam (Air Products), Rasmus Find and Mr. Delef (Union Engineering), Jim Davison (IEA GHG), Tom Kreutz (Princeton University), Alaa-Eldin Adris (Membrane Reactor Technologies), Kristin Jordal (Vattenfall), Isama Yasuda, Yoshinori Shirasaki and Tetsu Yamagishi (Tokyo Gas Company), Paul Feron (TNO), Shigeyuki Uemiya (Gifu University), Kas Hemmes (Delft University), Peter Middleton (BP), Carlo Hamelinck (Ecofys), Bibi Dauvillier, Laurens Witjens and Harry Oonk (University of Utrecht).

\section{References}

[1] Simbeck DR, Chang E. Hydrogen supply: cost estimate for hydrogen pathways - scoping analysis. Report no. NREL/SR-54032525. Mountain View, CA: NREL; 2002.

[2] Ogden JM. Hydrogen energy systems studies. Report no. NREL/CP-570-26938. Golden, CO: NREL; 1999.

[3] Ogden J. Review of small stationary reformers for hydrogen production. Report no. IEA/H2/TR-02/002. Princeton, USA: Princeton University; 2001.

[4] Jordal K, Bredesen R, Kvamsdal HM, Bolland O. Integration of $\mathrm{H}_{2}$-separating membrane technology in gas turbine processes for $\mathrm{CO}_{2}$ sequestration. In: Gale J, Kaya Y, editors. Proceedings of the 6th International Conference on Greenhouse Gas Control Technologies, Kyoto, Japan, vol. I. Amsterdam: Pergamon Press; 2003, p. 135-140.

[5] Wurster R. Pathways to a hydrogen refuelling infrastructure between today and 2020 - time scale and investment costs. In: Fuel cell teach-in European Commission DGTren. Brussels, Belgium: L-B-Systemtechnik GmbH; 2002.

[6] Kikuchi E. Membrane reactor application to hydrogen production. Catal Today 2000;56(1-3):97-101.

[7] Adris AM, Lim CJ, Grace JR. The fluidized-bed membrane reactor for steam methane reforming: model verification and parametric study. Chem Eng Sci 1997;52(10):1609-22.

[8] Dittmeyer R, Hollein V, Daub K. Membrane reactors for hydrogenation and dehydrogenation processes based on supported palladium. J Mol Catal A: Chemical 2001;173(1-2):135-84.

[9] Ledjeff-Hey K, Formanski V, Kalk T, Roes J. Compact hydrogen production systems for solid polymer fuel cells. J Power Sources 1998;71(1-2):199-207.

[10] TGC. Website information. Tokyo Gas Company, 2004. See also: http://www.tokyo-gas.co.jp/index_e.html

[11] MRT. Membrane reactor performance. Membrane Reactor Technologies, 2003. See also: www.membranereactor.com 
[12] Oklany JS, Hou K, Hughes R. A simulative comparison of dense and microporous membrane reactors for the steam reforming of methane. Appl Catal A: General 1998;170(1):13-22.

[13] Shu J, Grandjean BPA, Kaliaguine S. Methane steam reforming in asymmetric Pd- and Pd-Ag/porous SS membrane reactors. Appl Catal A: General 1994;119(2):305-25.

[14] Lin Y, Liu S, Chuang C, Chu Y. Effect of incipient removal of hydrogen through palladium membrane on the conversion of methane steam reforming: experimental and modeling. Catal Today 2003;82(1-4):127-39.

[15] Adris AM, Pruden BB, Lim CC, Grace J. On the reported attempts to radically improve the performance of the SMR reactor. Canadian J Chem Eng 1996;74:177.

[16] Lin Y-M, Rei M-H. Process development for generating high purity hydrogen by using supported palladium membrane reactor as steam reformer. International J Hydrogen Energy 2000;25(3):211-9.

[17] Basile A, Paturzo L. An experimental study of multilayered composite palladium membrane reactors for partial oxidation of methane to syngas. Catal Today 2001;67(1-3):55-64.

[18] Criscuoli A, Basile A, Drioli E, Loiacono O. An economic feasibility study for water gas shift membrane reactor. J Membr Sci 2001;181(1):21-7.

[19] Middleton P, Solgaard-Andersen H, Rostrup-Nielsen T. Hydrogen production with $\mathrm{CO}_{2}$ capture using membrane reactors. Carbon Capture Project, 2003. See also: http://www.co2captureproject.org/overview/overview.htm

[20] Roy S, Cox BG, Adris AM, Pruden BB. Economics and simulation of fluidized bed membrane reforming. Int J Hydrogen Energy 1998;23(9):745-52.

[21] Aasberg-Petersen K, Nielsen CS, Jorgensen SL. Membrane reforming for hydrogen. Catal Today 1998;46(2-3):193-201.

[22] Sanchez Marcano JG, Tsotsis TT. Catalytic membranes and membrane reactors. Weinheim: Wiley-VCH Verlag GmbH; 2002.

[23] Appl M. Modern production technologies, ammonia, methanol, hydrogen, carbon monoxide. CRU Publishing Ltd.; 1997.

[24] Myers DB, Ariff GD, James BD, Lettow JS, Thomas CE, Kuhn RC. Cost and performance comparison of stationary hydrogen fuelling appliances. Report no. Task 2. Arlington, VA: DTI, 2002.

[25] Damle AS. Recovery of carbon dioxide in advanced fossil fuel conversion processes using a membrane reactor. In: First National Conference on carbon sequestration. Washington: NETL; 2001.

[26] Buxbaum R. Membrane reactors, fundamental and commercial advantage, e.g. for methanol reforming. REB Research and Consulting, 1997. See also: www.rebresearch.com/MRessay.html

[27] ECN. Inorganic membranes_-brochure. Petten, Netherlands: Energy Centre Netherlands; 1996.

[28] Jansen D, Dijkstra JW. Personal communication. Petten, The Netherlands: ECN; 2003.

[29] Shah MM, Drnevich RF. Economic feasibility analysis of hydrogen production by integrated ceramic membrane system. In: 2002 DOE hydrogen review program. Golden, CO: NREL; 2002.

[30] Lin Y-M, Lee G-L, Rei M-H. An integrated purification and production of hydrogen with a palladium membrane-catalytic reactor. Catal Today 1998;44(1-4):343-9.

[31] Alderliesten PT, Bracht M. An attractive option for $\mathrm{CO}_{2}$ control in IGCC systems: water gas shift with integrated $\mathrm{H}_{2} / \mathrm{CO}$ separation (WIHYS) process. Report no. JOU2-CT92-0158. Petten, The Netherlands: ECN; 1997.

[32] Hou K, Hughes R. The effect of external mass transfer, competitive adsorption and coking on hydrogen permeation through thin Pd/Ag membranes. J Membr Sci 2002;206(1-2):119-30.

[33] Bus E. Poisoning of palladium membranes during separation of hydrogen from CPO-WGS product streams. Utrecht: Debije Institute, Utrecht University; 2002.

[34] Matthey J. Personal communication. London, UK: Johnson Matthey; 2004.

[35] Basile A, Paturzo L, Lagana F. The partial oxidation of methane to syngas in a palladium membrane reactor: simulation and experimental studies. Catal Today 2001;67(1-3):65-75.

[36] Marigliano G, Barbieri G, Drioli E. Equilibrium conversion for a Pd-based membrane reactor. Dependence on the temperature and pressure. Chem Eng Process 2003;42:231-6.

[37] Grace JR, Li X, Jim Lim C. Equilibrium modelling of catalytic steam reforming of methane in membrane reactors with oxygen addition. Catal Today 2001;64(3-4):141-9.

[38] Bracht M. Water gas shift membrane reactor for $\mathrm{CO}_{2}$ control in IGCC systems: techno-economic feasibility study. Energy Convers Manage 1997;38(Supplement):159-62.

[39] IEA GHG. Transmission of $\mathrm{CO}_{2}$ and energy. Report no. PH4/6. Stoke Orchard: International Energy Agency Greenhouse Gas R\&D Programme; 2002.

[40] Lattner JR, Harold M. Comparison of conventional and membrane reactor fuel processors for hydrocarbon-based PEM fuel cell systems. Int J Hydrogen Energy 2004;29:393-417.

[41] Wieland IS, Melin IT, Lamm IA. Membrane reactors for hydrogen production. Chem Eng Sci 2002;57(9):1571-6.

[42] Middleton P. Personal communication. London, UK: British Petroleum; 2004.

[43] Dijkstra JW. Personal communication. Petten, The Netherlands: Energy Centre Netherlands; 2004.

[44] Youngs W. Personal communication. Surrey, UK: Toromont Process Systems; 2004.

[45] Reichle D, Houghton J, Kane B, Ekmann J. Carbon sequestration, research and development. Report no. Washington DC, USA: Office of Fossil Energy, DOE; 1999.

[46] Birkestad H. Separation and compression of $\mathrm{CO}_{2}$ in an $\mathrm{O}_{2} / \mathrm{CO}_{2}$-fired power plant. Chalmers University of Technology; 2002.

[47] Find R, Delef. Personal communication. Copenhagen, Denmark: Union Engineering; 2004.

[48] Cownden R, Eiche M, Louie C, Watkins DS. Fuel cell electric power generation system. Ballard Generation Systems Inc., 2003. See also: www.ballard.com 
[49] Edlund DJ, Pledger WA. Hydrogen producing fuel processing system. United States: IdaTech; 2001. See also: www.idatech.com

[50] Bonk SP, Scheffler GW, Foley PF, Corrigan TJ, Sederquist RA, Kocum FA. Hydrocarbon fuel gas reformer assembly for a fuel cell power plant. United States: International Fuel Cells, LLC; 2001. See also: http://www.fuelcelltoday.com/PatentListings/ PatentListingsExternal/DisplayPatent/0,1702,361,00.html\#

[51] Fuel Cell Today. Hydrogen infrastructure 2003, 2003. See also: www.fuelcelltoday.com

[52] Thomas CE, Reardon JP, Lomax FD, Pinyan J, Kuhn IF. Distributed hydrogen fueling systems analysis. In: 2001 DOE hydrogen program review. Golden, CO: NREL; 2001.

[53] Neumann DWR. Dynamic reactor operation and high-temperature catalysis: direct oxidation of methane in a reverse-flow reactor. Ph.D. Thesis. Koln: University of Koln; 1999.

[54] Van Beurden P. On the catalytic aspects of steam-methane reforming. Report no. ECN-I-04-003. Petten, The Netherlands: ECN; 2004.

[55] Peña MA, Gómez JP, Fierro JLG. New catalytic routes for syngas and hydrogen production. Appl Catal A: General $1996 ; 14$.

[56] Jorgensen SL, Nielsen PEH, Lehrmann P. Steam reforming of methane in a membrane reactor. Catal Today 1995;25(3-4):303-7.

[57] Assaf EM, Jesus CDF, Assaf JM. Mathematical modelling of methane steam reforming in a membrane reactor: an isothermic model. Braz J Chem Eng 1998; Volume 2(No. 2).

[58] Jordal K, Bredesen R, Kvamsdal HM, Bolland O. Integration of H2-separating membrane technology in gas turbine processes for CO2 capture. Energy 2004;29:1269-78.

[59] Tijmensen MJA, Faaij APC, Hamelinck CN, van Hardeveld MRM. Exploration of the possibilities for production of Fischer Tropsch liquids and power via biomass gasification. Biomass Bioenerg 2002;23(2):129-52.

[60] Hamelinck CN, Faaij APC. Future prospects for production of methanol and hydrogen from biomass. Report no. NWS-E-2001-49. Utrecht, The Netherlands: Utrecht University, Copernicus Institute for Sustainable Development and Innovation, Department of Science, Technology and Society; 2001.

[61] Coulson JM, Richardson JF, Sinnot RK. Chemical engineering. Oxford: Pergamon Press; 1990.

[62] Brennan D. Process industry economics - an international perspective. Rugby, UK: IchemE; 1998.

[63] Bovag. Mobility in figures (Mobiliteit in cijfers). Bovag, 2004 [in Dutch]. See also: www.bovagrai.nl

[64] Klassen A. Personal communication. Vancouver, Canada: Membrane Reactor Technologies; 2005.

[65] Metalprices. Market prices for metals. Metalprices, 2005. See also: www.metalprices.com

[66] Dijkstra JW. Personal communication. Petten, The Netherlands: Energy Centre Netherlands; 2005.

[67] DTI. Industrial Electricity Prices EU. DTI, 2004. See also: www.dti.gov.uk

[68] Yasuda I, Shirasaki Y, Tsuneki T, Asakura T, Kataoka A, Shinkai H, et al. Development of membrane reformer for highly efficient hydrogen production from natural gas. Report no. unavailable. Tokyo, Japan: Japan Gas Association; 2004.

[69] Adris AM. Personal communication. Vancouver, Canada: Membrane Reactor Technologies; 2003.

[70] Correia L. Personal communication. Petten, The Netherlands: Energy Centre Netherlands; 2005.

[71] Sibley SF. Flow studies for recycling metal commodities in the United States. Report no. TS214 .F56 2004. Reston, VA: US Dept. of the Interior US Geological Survey; 2004.

[72] Johannessen E, Jordal K. Study of a $\mathrm{H}_{2}$ separating membrane reactor for methane steam reforming at conditions relevant for power processes with $\mathrm{CO}_{2}$ capture. In: unavailable, editor. Ecos Conference. Copenhagen, Denmark; 2003.

[73] Chen Z, Yan Y, Elnashaie SSEH. Novel circulating fast fluidized-bed membrane reformer for efficient production of hydrogen from steam reforming of methane. Chem Eng Sci 2003;58(19):4335-49.

[74] Julbe A, Guizard C. Role of membranes and membrane reactors in the hydrogen supply of fuel cells. Ann Chim Sci Mater 2001;26(4):79-92.

[75] Basile A, Chiappetta G, Tosti S, Violante V. Experimental and simulation of both Pd and Pd/Ag for a water gas shift membrane reactor. Sep Purif Technol 2001;25(1-3):549-71.

[76] Lin Y-M, Rei M-H. Separation of hydrogen from the gas mixture out of catalytic reformer by using supported palladium membrane. Sep Purif Technol 2001;25(1-3):87-95.

[77] Amandusson H, Ekedahl L-G, Dannetun H. The effect of $\mathrm{CO}$ and $\mathrm{O}_{2}$ on hydrogen permeation through a palladium membrane. Appl Surf Sci 2000;153(4):259-67.

[78] IEA GHG. Reduction of $\mathrm{CO}_{2}$ emissions by adding hydrogen to natural gas. Report no. PH4/24. Stoke Orchard: International Energy Agency Greenhouse Gas R\&D Programme; 1996.

[79] Uemiya S. Brief review on steam reforming using metal membrane reactor. Report no. Gifu, Japan: Gifu University, Faculty of Engineering; 2003.

[80] ChevronTexaco. Halias Fuel Processor brochure. 2003.

[81] Feiken. Personal communication. Groningen, The Netherlands: Gasunie; 2003.

[82] Fueleconomy. Fuel economy FCV's. 2004. See also: www.fueleconomy.com

[83] Ogden JM. Developing an infrastructure for hydrogen vehicles: a Southern California case study. Int J Hydrogen Energy 1999;24:709-30.

[84] IEA GHG. Decarbonisation of fossil fuels. Report no. PH2/19. Stoke Orchard: International Energy Agency Greenhouse Gas R\&D Programme; 1996.

[85] Christiansson L. Diffusion and learning curves of renewable energy technologies. Report no. WP-95-126. Laxenburg, Austria: International Institute for Applied Systems Analysis, 1995.

[86] Katofsky RE. The production of fluid fuels from biomass. MSc thesis. Princeton: Princeton University; 1993. 
[87] Neij L, Andersen PD, Durstewitz M, Helby P, Hoppe-Kilpper M, Morthorst PE. Experience Curves: a Tool for Energy Policy Assessment. Report no. Lund University, 2003.

[88] Harmon C. Experience curves of photovoltaic technology. Report no. IR-00-014. Laxenburg, Austria: IIASA, 2000.

[89] Kitco. Commodity prices. 2004. See also: www.kitco.com

[90] Joffe D. Personal communication. London, UK: Imperial College; 2004.

[91] Hamelinck CN, et al. Potential for $\mathrm{CO}_{2}$ sequestration and enhanced coalbed production in the Netherlands. Report no. ISBN 905847-020-4, Utrecht, November, 2001.

[92] Ogden JM. Internal MEMO: Feasibility and cost of long distance pipeline transmission of hydrogen. Princeton, NJ: Princeton University; 1997.

[93] Bock BR, Rhudy RG, Nichols DE. Economic evaluation of $\mathrm{CO}_{2}$ sequestration technologies. Report no. DE-FC26-00NT40937, DOE; 2001.

[94] Hekkert MP, Faaij APC, Hendriks F, Neelis ML. Natural gas as an alternative to crude oil in automotive fuel chains well-to-wheel analysis and transition strategy development. Energy Policy 2005;33(5):579-94.

[95] Amos WA. Cost of storing and transporting hydrogen. Report no. NREL/TP-570-25106. Golden, CO: NREL; 1998.

[96] DTI. Unleaded petrol and diesel prices EU. DTI, 2004. See also: www.dti.gov.uk

[97] Hamelinck CN. Outlook for advanced biofuels. PhD thesis, Utrecht: University of Utrecht, Copernicus Institute for Sustainable Development and Innovation, Department of Science, Technology and Society; 2004.

[98] Aspen. Aspen Plus user guide. Aspen Systems Incorporated, 2003.

[99] Branan CR. Rules of thumb for chemical engineers. Oxford: Butterworth-Heineman; 2002.

[100] Kongsjorden H, Karstad O, Torp TA. Saline aquifer storage of carbon dioxide in the sleipner project. Waste Management 1998;17:303-8.

[101] Ullmann. Ullmann's Encyclopedia of Industrial Chemistry. In: Weinheim, Germany: Wiley-VCH; 1997

[102] Moore RB. R\&D of a direct hydrogen fueled PEM fuel cell system for transportation applications. In: Ford hydrogen infrastructure study. Report no. Ford Motor Company; 1996.

[103] Chiesa P, Kreutz T, Williams B. Analysis of hydrogen and co-product electricity production from coal with near zero pollutant and $\mathrm{CO}_{2}$ emissions using an inorganic hydrogen separation membrane reactor. In: Second annual conference on carbon sequestration, Alexandria, VA; 2003.

[104] Perry RH, Green DW. Perry's chemical engineers' handbook. New York, NY: McGraw-Hill; 2000.

[105] Remer RS, Cahi L. Design cost factors for scaling up engineering equipment. Chem Eng Prog 1990;86:77-81.

[106] DACE. Prijzenboekje Dutch Association of Cost Engineers; 2002.

[107] Atlas Copco. Personal communication. Hemel Hempstead, UK: Atlas Copco; 2003.

[108] EPA. Lessons learned from Natural Gas STAR partners; Replacing glycol dehydrators with dessicant dehydrators. Washington, DC: United States Environmental Protection Agency; 2003.

[109] Kikuchi E, Nemoto Y, Kajiwara M, Uemiya S, Kojima T. Steam reforming of methane in membrane reactors: comparison of electroless-plating and CVD membranes and catalyst packing modes. Catal Today 2000;56(1-3):75-81.

[110] Lasher S, Stratonova M, Thijssen J. Hydrogen technical analysis. In: none, editor. Proceedings of the 2002 US DOE hydrogen program review. Golden, CO: NREL; 2002.

[111] Lin Y-M, Rei M-H. Study on the hydrogen production from methanol steam reforming in supported palladium membrane reactor. Catal Today 2001;67(1-3):77-84.

[112] Gallucci F, Paturzo L, Basile A. A simulation study of the steam reforming of methane in a dense tubular membrane reactor. Int $\mathbf{J}$ Hydrogen Energy 2004;29(6):611-7.

[113] Ogden JM. Modelling infrastructure for a fossil hydrogen energy system. In: Gale J, Kaya Y, editors. Proceedings of the 6th International Conference on Greenhouse Gas Control Technologies, Kyoto, Japan, vol. II. Amsterdam: Pergamon Press; 2003. p. 1069-1074.

[114] Tillemans FWA, Ouden ACBd. Brandstofcelbussen en -distributievrachtwagens in de stedelijke omgeving. Report no. ECN-C-03009. Petten: ECN; 2003.

[115] Basye L, Swaminathan S. Hydrogen production costs - a survey. Report no. DOE/GO/10170-T18. Bethesda: Sentech, Inc, 1997.

[116] Uhde. Gas processes in hydrocarbon processing: hydrogen. Gulf Publishing Company; 2002.

[117] Foster-Wheeler. Gas processes in hydrocarbon processing: hydrogen. Gulf Publishing Company; 2002.

[118] Ogden JM. Hydrogen energy systems studies. Report no. NREL/CP-570-26938. Princeton, USA: Centre for Energy and Environmental Studies, Princeton University; 1996.

[119] Thomas C, James B, Kuhn IF, Lomax FD, Baum GN. Ford hydrogen infrastructure study summary. Report no. 47-2-R3115. Arlington, VA: Directed Technologies Inc.; 1997.

[120] ADL. Guidance for transportation technologies: fuel choice for fuel cell vehicles. Cambridge, MA, 2002 [quoted by Shayegan 2003 ].

[121] Tillemans FWA, Groot Ad. Evaluation of benefits and barriers of hydrogen in residential districts. Report no. ECN-C-01-020. Petten: ECN; 2002.

[122] Kumar RV, Kastanas GN, Barge S, Zamansky V, Seeker R. Autothermal cyclic reforming based fueling system. In: FY 2002 progress report. US: DOE; 2002.

[123] HyWeb. Website. See also: http://www.hyweb.de/Knowledge/w-i-energiew-eng4.html

[124] Drnevich R. Hydrogen delivery: liquefaction and compression presentation. Praxair, 2004. See also: http://www.eere.energy.gov/ hydrogenandfuelcells/pdfs/liquefaction_comp_pres_praxair.pdf 
[125] Ogden JM, Williams RH, Larson ED. Toward a hydrogen-based transportation system. Report no. unavailable. Princeton: Centre for Energy and Environmental Studies, Princeton University; 2001.

[126] Berry GD, Pasternak AD. Hydrogen as a future transportation fuel. Energy 1996;21(4):289-303.

[127] Ford Motor Company. Ford hydrogen infrastructure study. Report no. 47-2-R3115. Inc. Allentown, PA: Ford Motor Company; 1996.

[128] Ferrel J, Kotar A, Stern S. Direct hydrogen fueled PEM fuel cell system for transportation applications. In: Ford Hydrogen Infrastructure Project. Report no. unavailable. New York: BOC Gases; 1996.

[129] Damen KJ, van Troost M, Faaij APC, Turkenburg WC. A comparison of hydrogen and electricity production systems with $\mathrm{CO}_{2}$ capture and storage. Part A: Review and selection of promising conversion and capture technologies. Progress in Energy and Combustion Science, in press.

[130] Socolow R. Fuels decarbonization and carbon sequestration: Report of a workshop. Report no. 302. Princeton: CEES; 1997.

[131] Hendriks C. Carbon dioxide removal from coal-fired power plants. PhD thesis. Utrecht: Utrecht University; 1994.

[132] Chapel DG, Mariz CL, Ernest J. Recovery of $\mathrm{CO}_{2}$ from flue gases: commercial trends. In: Canadian Society of Chemical Engineers annual meeting. Saskatoon, Canada: 1999.

[133] Kreutz TG, Williams RH, Socolow RH, Chiesa P, lozza G. Production of hydrogen and electricity from coal with $\mathrm{CO}_{2}$ capture. In: Gale J, Kaya Y, editors. GHGT-6. Kyoto, Japan: Pergamon; 2002.

[134] Wildenborg AFB, Hendriks C, Van Wees JD, Floris F, Van der Meer LGH, Schuppers J, et al. Kostencalculatie van CO ${ }_{2}^{-}$ verwijdering via ondergrondse opslag. Report no. TNO-NITG-99-128-B. Haarlem: NITG-TNO; 1999.

[135] Hendriks C, Graus W, van_Bergen F. Global carbon dioxide storage potential and costs. Report no. EEP-02001. Utrecht: Ecofys; 2002. 